\title{
orb is required for anteroposterior and dorsoventral patterning during Drosophila oogenesis
}

\author{
Lori B. Christerson and Dennis M. McKearin
}

Department of Biochemistry, University of Texas Southwestern Medical Center, Dallas, Texas 75235-9038 USA

\begin{abstract}
We describe mutations in the orb gene, identified previously as an ovarian-specific member of a large family of RNA-binding proteins. Strong orb alleles arrest oogenesis prior to egg chamber formation, an early step of oogenesis, whereas females mutant for a maternal-effect lethal orb allele lay eggs with ventralized eggshell structures. Embryos that develop within these mutant eggs display posterior patterning defects and abnormal dorsoventral axis formation. Consistent with such embryonic phenotypes, orb is required for the asymmetric distribution of oskar and gurken mRNAs within the oocyte during the later stages of oogenesis. In addition, double heterozygous combinations of orb and grk or orb and top/DER alleles reveal that mutations in these genes interact genetically, suggesting that they participate in a common pathway. Orb protein, which is localized within the oocyte in wild-type females, is distributed ubiquitously in stage 8-10 orb mutant oocytes. These data will be discussed in the context of a model proposing that Orb is a component of the cellular machinery that delivers mRNA molecules to specific locations within the oocyte and that this function contributes to both $D / V$ and $A / P$ axis specification during oogenesis.
\end{abstract}

[Key Words: RNA binding; oogenesis; dorsoventral; posterior group; polarity; RNA localization]

Received October 5, 1993; accepted in revised form January 20, 1994.

One of the earliest events in embryonic development is the establishment of anteroposterior $(\mathrm{A} / \mathrm{P})$ and dorsoventral $(\mathrm{D} / \mathrm{V})$ axes, patterning processes that are particularly well characterized in Drosophila (for review, see St Johnston and Nüsslein-Volhard 1992). The Drosophila embryo organizes its body plan by using maternally inherited positional information. The organization of the anterior and posterior patterns in the embryo is dependent on the asymmetric distribution of specific mRNAs and proteins within the egg during oogenesis (for review, see Lasko 1992; Lehmann 1992; St Johnston and Nüsslein-Volhard 1992). Transcripts for the anterior determinant bicoid $(b c d)$ are localized in the oocyte cytoplasm at the anterior pole of the egg and are translated after fertilization to produce an anterior-to-posterior concentration gradient of Bicoid protein (Frigerio et al. 1986; Berleth et al. 1988; Driever and Nüsslein-Volhard 1988; St Johnston et al. 1989). Mutations that disrupt $b c d$ mRNA localization result in distortion of pattern elements along the A/P axis (Schüpbach and Wieschaus 1986; Frohnhöfer and Nüsslein-Volhard 1987; Stephenson and Mahowald 1987). In the posterior patterning system, transcripts for the posterior group gene oskar (osk) are among the first that must be localized to the oocyte posterior pole for assembly of a specialized cytoplasm, the polar plasm (Lehmann and Nüsslein-Volhard 1986; Ephrussi et al. 1991; Kim-Ha et al. 1991). The polar plasm contains two localized signals: the posterior de- terminant nanos, which is required for normal abdominal segmentation in the embryo (Wang and Lehmann 1991; Gavis and Lehmann 1992), and a second signal that directs the formation of the posterior pole cells, the germ cell precursors (Ephrussi and Lehmann 1992).

The D/V pattern in the embryo is thought to form largely independently of the A/P pattern (St Johnston and Nüsslein-Volhard 1992) and probably is determined by positional information present in the vitelline membrane of the egg (Stein et al. 1991; Stein and NüssleinVolhard 1992). The vitelline membrane, along with the eggshell, is secreted during oogenesis by the follicle cells that surround the oocyte (Mahowald and Kambysellis 1980). The determination of follicle cell states along the $\mathrm{D} / \mathrm{V}$ axis requires signaling between the oocyte and follicle cells (Manseau and Schüpbach 1989; Schüpbach et al. 1991). Distribution of the signal to a limited number of follicle cells produces a distinctly patterned dorsal eggshell surface. Signal production may be associated with the oocyte nucleus, because only the follicle cells overlying the oocyte nucleus adopt dorsal fates and laser ablation of the oocyte nucleus blocks any follicle cells from becoming dorsal (Montell et al. 1991).

Genetic analysis of maternal-effect mutations has identified a number of genes required to establish the $\mathrm{D} / \mathrm{V}$ axis of both the eggshell and embryo. Females mutant for the genes $f_{S}(1) K 10$ and squid (sqd) produce eggshells and embryos that are dorsalized and deficient in 
ventral structures (Wieschaus et al. 1978; Kelley 1993). Since this phenotype suggests that too many follicle cells receive a dorsalizing signal, these genes may act to restrict the expression of the signal temporally and/or spatially. The opposite phenotype is produced by gurken (grk), torpedo (top/DER), cornichon (cni), rhomboid (rho), and brainiac (brn) mutations, which cause cells that normally develop as dorsal to adopt a ventral fate on the eggshell (Schüpbach 1987; Ashburner et al. 1990; Schüpbach et al. 1991; Goode et al. 1992; Ruohola-Baker et al. 1993). The embryos within grk, top/DER, cni, and rho eggs are ventralized as well. top/DER and rho activities are required in the follicle cells during oogenesis for dorsal follicle cell determination (Schüpbach 1987; Ruohola-Baker et al. 1993), whereas grk, cni, and brn activities are required in the germ line for proper dorsal follicle cell fate (Schüpbach 1987; Schüpbach et al. 1991; Goode et al. 1992). top/DER is an oogenesis-specific allele of the Drosophila epidermal growth factor receptor (DER; Schejter and Shilo 1989; Price et al. 1989) and is hypothesized to be a receptor for the dorsalizing signal (Schüpbach 1987; Price et al. 1989). Recently, Neuman-Silberberg and Schüpbach (1993) have determined that grk encodes a transforming growth factor- $\alpha$ (TGF$\alpha$ )-like protein and have shown that grk transcripts are asymmetrically localized to the dorsal corner of the oocyte. They have postulated that the dorsal localization of grk mRNA may result in a spatially restricted ligand that asymmetrically activates the top/DER receptor.

Mutations in cappuccino (capu) and spire (spir) produce both ventralized and dorsalized eggshells and embryos (Manseau and Schüpbach 1989; Neuman-Silberberg and Schüpbach 1993; L. Manseau, pers. comm.) and also block abdominal segmentation in the embryo (Manseau and Schüpbach 1989). Thus, these genes are required for the formation of both the $A / P$ and $D / V$ axes (Manseau and Schüpbach 1989), suggesting that a common process may be involved in the establishment of both polarities. In this report we describe a third gene, $o r b$, that is necessary for proper $\mathrm{A} / \mathrm{P}$ and $\mathrm{D} / \mathrm{V}$ patterning in the oocyte and embryo. We find that orb is required for the formation of the dorsal surfaces of the eggshell and interacts genetically with grk and top/DER. We also show that mutation of the orb locus results in both expansion of ventral fates and posterior patterning defects in the embryo. In addition, we describe a strong orb mutation that disrupts oogenesis by arresting cyst development prior to egg chamber formation.

The orb gene product contains domains that match the consensus sequences of the RNA recognition motif (RRM) family of RNA-binding proteins (Lantz et al. 1992). Members of this family bind a wide variety of RNA molecules (Kenan et al. 1991; Kim and Baker 1993). We show that orb is required for the distribution of $g r k$ and osk mRNAs within the oocyte during the later stages of oogenesis. These results suggest that the RRM sequence similarity may be of functional significance. On the basis of these data, we postulate that Orb is a component of cellular machinery in the egg chamber that asymmetrically distributes mRNA molecules to specific regions of the oocyte.

\section{Results \\ Identification of a mutation that arrests cyst development}

Each Drosophila ovary is composed of $\sim 15-20$ ovarioles, each containing egg chambers at different stages of development (for review, see King 1970; Mahowald and Kambysellis 1980; Spradling 1993b|. At the anterior end of each ovariole is a region called the germarium (Fig. 1A). At the onset of oogenesis, cystoblasts at the anterior end of the germarium undergo four mitotic divisions with incomplete cytokinesis, producing syncytial clusters (cysts; Spradling 1993a) of 16 cystocytes interconnected by cytoplasmic bridges (ring canals; Brown and King 1964; Xue and Cooley 1993|. The presumptive oocyte resides at the posterior end of the cluster, whereas the more anterior cells develop as nurse cells and synthesize products that will be transported into the oocyte. Somatically derived follicle cells surround the cyst in a uniform monolayer to form the egg chamber.

The orb $b^{d e c}$ allele was identified in a collection of enhancer-trap female sterile mutants and contains a transposon insertion (referred to as $P\left[1 a c Z-r y^{+}\right] 94 E$ ) in $94 \mathrm{E}$ on the right arm of the third chromosome (see Table 1A for orb alleles used in this study). Ovaries of or $b^{d e c}$ females are tiny, perhaps $1-5 \%$ of wild-type volume. Each or $b^{d e c}$ ovariole consists of a germarium-like region and occasionally one or two egg chambers. These egg chambers are often empty, indicating that the germ cells have degenerated. Comparing or $b^{\text {dec }}$ germaria to wild type using differential interference contrast (DIC) microscopy (Fig. $1 B, C$ ), we found that cystocytes at the anterior end (region 1) appear normal. These cells are expected to be two-, four-, and eight-cell clusters that arise from the mitotic divisions of the cystoblasts. However, beginning in the germarial mid-region when cystocytes have completed their divisions, cellular morphology begins to appear aberrant. In this region, blebs appear on the surfaces of the or $b^{d e c}$ cystocytes (Fig. 1C), and these cells do not grow in volume or undergo the extensive genomic polyploidization that characterizes their wild-type counterparts (data not shown). By the time that follicle cells have surrounded the germ-line cells to form the egg chamber, the cystocytes appear to have partially or completely degenerated.

The disruption of cystocyte differentiation in orb dec ovaries can be seen more clearly by using rhodaminelabeled phalloidin to stain F-actin in the cortical cytoskeleton of cystocytes and follicle cells as well as the ring canals in the cystocytes. Figure 1, D and E, shows confocal images of rhodamine-phalloidin-stained wildtype and mutant germaria, respectively. Consistent with the data obtained from visible light microscopy (Fig. 1, B and $\mathrm{Cl}$, the cells in the anterior region of mutant germaria appeared similar to those seen in wild type, whereas 

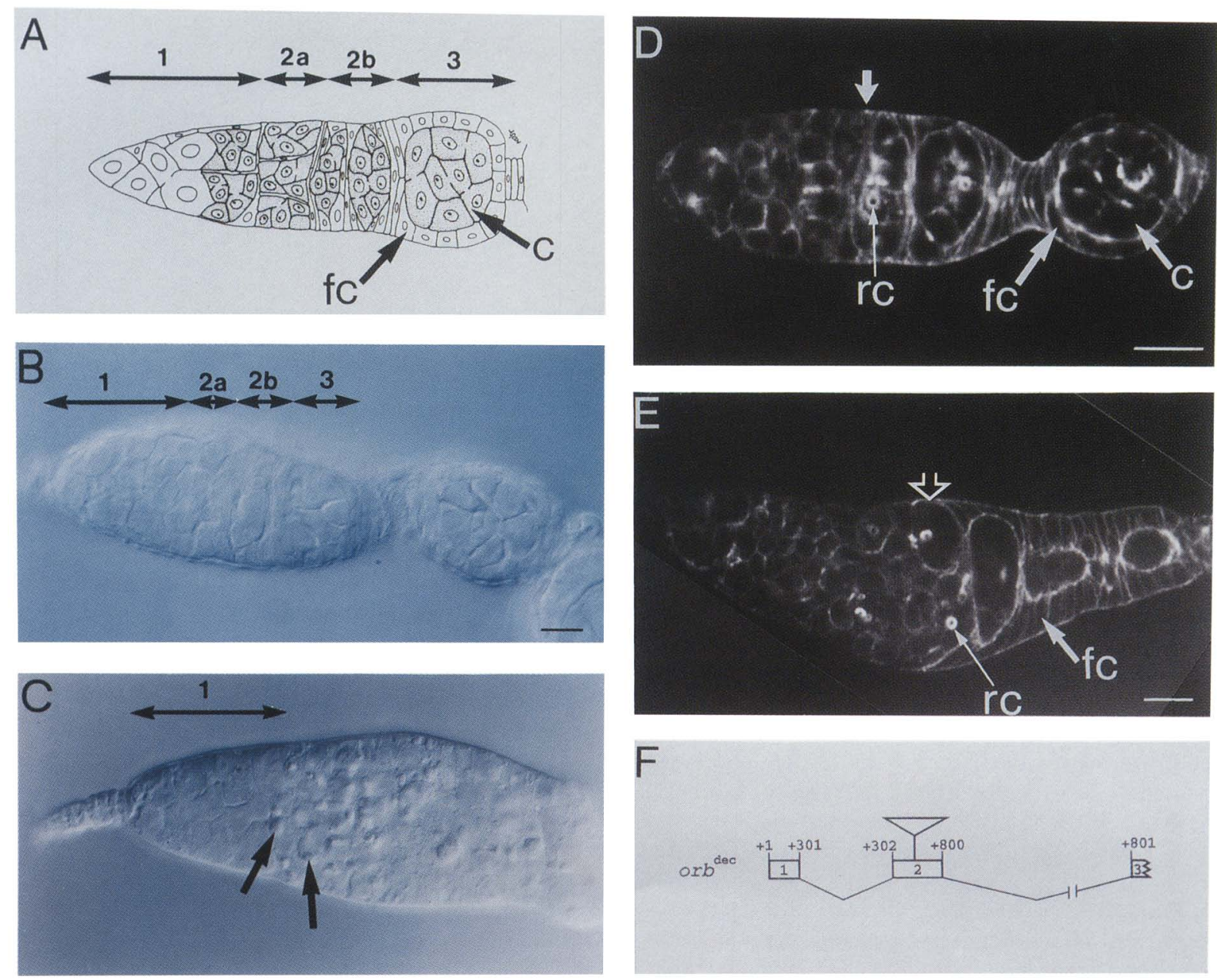

Figure 1. The $o r b^{d e c}$ transposon insertion produces arrest of early oogenesis. $(A)$ Schematic diagram of the Drosophila germarium (adapted from Mahowald and Strasshiem 1970). At the anterior end of the germarium (left), stem cell daughters (cystoblasts) divide mitotically with incomplete cytokinesis to produce $2-, 4-, 8-$, and 16-cell syncytial clusters. Germarial region 1 contains the stem cells and the mitotic cystoblasts. Germarial region 2a contains the newly formed 16-cell clusters. Follicle cells surround the 16-cell clusters to produce lens-shaped egg chambers in region $2 \mathrm{~b}$. Egg chambers, composed of cystocytes (c) and follicle cells (fc) assume a spherical shape in germarial region $3 .(B)$ Wild-type ovariole. Germarial regions $1-3$ are indicated. A more mature egg chamber is present at the posterior end (right) of the germarium. Bar, $10 \mu \mathrm{m}$ (applies to $B$ and $C) .(C)$ orb $b^{d e c}$ ovariole. Cells at the anterior end (approximately region 1) appear normal, followed by cellular blebs (arrows) in the mid-region that are presumed to be evidence of degenerating cells and cellular debris. The disruption of germarial morphology that is caused by the mutation allows only an approximate designation of the germarial regions. $(D)$ Confocal image of a wild-type ovariole stained with rhodamine-phalloidin. Large germ-line cells are outlined by the reagent in the anterior half of the germarium. Immediately posterior to the midpoint (arrow at top) and spanning the width of the germarium can be seen a lens-shaped cluster of cystocytes being surrounded by migrating follicle cells. Two more mature egg chambers are visible in this micrograph; one in region 3 and a larger, more spherical chamber that has been released from the germarium. Note also the easily detectable ring canals (rc) in egg chambers at the lens-shaped stage and beyond. Bar, $10 \mu \mathrm{m}$ (applies to $D$ and $E)$. $(E)$ orb $b^{d e c}$ ovariole stained with rhodamine-phalloidin. The cortical pattern of F-actin in cells at the anterior end of the germarium appears similar to wild type. Cyst assembly appears aberrant in the mid-region and completed cysts appear devoid of cystocytes (see text). The open arrow marks a cyst containing a ring canal but apparently without cystocytes. Note that $D$ and $E$ do not represent confocal images of $B$ and $C$. $(F)$ Schematic representation of the $5^{\prime}$ portion of the or $b$ gene, indicating boundaries between exons (open boxes) and introns (solid lines). The or $b^{d e c}$ mutagenic transposon insertion site (between nucleotides +499 and +500 ) in exon 2 is indicated. PCR and sequence analysis of the orb gene has identified a previously unrecognized intron at nucleotide position +301 (Lantz et al. 1992; see Materials and methods).

the mid-region of mutant germaria contained only poorly formed cystocyte clusters and little evidence of enclosure by follicle cells. This region corresponds to the area of cellular blebbing seen in the DIC micrographs such as Figure 1C. When enclosed clusters were detect- able, the central cavity, which should be occupied by cystocytes, appeared empty. Often, ring canals appeared to be free floating and not embedded in membrane (Fig. $1 \mathrm{E}$, e.g., see cyst marked by open arrow). From these observations, we conclude that the or $b^{d e c}$ mutation dis- 
Table 1. Mutations used in this study

\begin{tabular}{|c|c|c|}
\hline $\begin{array}{l}\text { A. orb mutations } \\
\text { Allele }\end{array}$ & Phenotype & Source/reference \\
\hline $\begin{array}{l}\text { orb } b^{\text {dec }} \\
\text { orb } b^{F 343} \\
\text { orb } \\
D f(3 R) M S u 244\end{array}$ & $\begin{array}{l}\text { degenerating cysts } \\
\text { degenerating cysts } \\
\text { maternal-effect lethal } \\
\text { strong Minute and recessive lethal }\end{array}$ & $\begin{array}{l}\text { A.C. Spradling; this work } \\
\text { Lantz et al. }(1994) \\
\text { this work } \\
\text { Reuter et al. (1986) }\end{array}$ \\
\hline $\begin{array}{l}\text { B. Mutations us } \\
\text { Gene }\end{array}$ & $\begin{array}{l}\text { test genetic interactions } \\
\text { Phenotype of eggshells and embryos }\end{array}$ & Source/reference \\
\hline $\begin{array}{l}\operatorname{grk}^{H K 36} \\
\operatorname{grk}^{H G 21} \\
\text { top }^{\mathrm{CO}} \\
\text { top }^{1} \\
\text { cni }^{A A 12} \\
\text { fs }_{S}(1) K 10^{L M O O}\end{array}$ & $\begin{array}{l}\text { intermediate and strong ventralization } \\
\text { weak and intermediate ventralization } \\
\text { embryonic lethality } \\
\text { weak and intermediate ventralization } \\
\text { strong ventralization } \\
\text { strong dorsalization }\end{array}$ & $\begin{array}{l}\text { Schüpbach (1987) } \\
\text { Schüpbach (1987) } \\
\text { Clifford and Schüpbach (1989); Price et al. (1989) } \\
\text { Schüpbach (1987) } \\
\text { Ashburner et al. (1990) } \\
\text { T. Schüpbach }\end{array}$ \\
\hline
\end{tabular}

rupts cyst formation near the time that the 16-cell cluster is formed and causes cystocytes to degenerate.

Rhodamine-phalloidin staining of or $b^{d e c}$ ovaries revealed that follicle cell migrations /to surround the cystocyte clusters/ appeared retarded, raising the possibility that $o r b^{+}$activity might be required in the follicle cells. However, molecular evidence supports a role that is restricted to the germ-line cells. In females that are heterozygous for the orb dec allele, LacZ expression (from the mutagenic $P\left[1 a c Z-r^{+}\right] 94 E$ transposon) is detected only in the germ-line cells of the egg chamber throughout oogenesis (data not shown). In addition, the absence of the orb transcript in germ-line-less flies (Lantz et al. 1992) and the restriction of orb mRNA (Lantz et al. 1992) and protein expression (Lantz et al. 1994; this paper) to the germ line strongly suggests that orb $^{+}$activity is required only in germ-line cells. Therefore, we suspect that egg chamber formation is retarded in orb $b^{d e c}$ ovaries because clusters of degenerating cystocytes are poor substrates for follicle cell migrations.

We confirmed that $P\left[1 a c Z-r y^{+}\right] 94 E$ was the cause of the mutant phenotype by two methods. First, a chromosome deficient for the 94E region, $D f(3 R) M S u 244$ (Table 1A), failed to complement the or $b^{d e c}$ phenotype. Second, precise excision of the transposon resulted in simultaneous reversion of the mutant phenotype to wild type. or $b^{d e c}$ was judged to be a strong loss-of-function allele because orb $b^{\text {dec }} / D f(3 R) M S u 244$ flies displayed the same phenotype as or $b^{\text {dec }}$ homozygotes.

\section{Molecular analysis of the orb ${ }^{\mathrm{dec}}$ allele}

The orb locus was cloned from the or $b^{d e c}$ allele using transposon sequences to recover genomic DNA flanking $P\left[1 a c Z-r y^{+}\right] 94 E$. By comparing the orb cDNA sequence (Lantz et al. 1992) with that of the orb ${ }^{\text {dec }}$ allele, we determined that $P\left[\mathrm{lacZ}-\mathrm{ry}{ }^{+}\right] 94 \mathrm{E}$ was located in the $5^{\prime}$-untranslated region (UTR) of the female orb transcript between positions +499 nucleotides and +500 nucleotides (Fig. 1F). Consistent with genetic results, or $b^{\text {dec }}$ behaves as a strong loss-of-function allele, since Northern analysis and in situ hybridization to ovaries revealed that homozygous or $b^{d e c}$ females produced little or no orb mRNA (data not shown), and immunoblotting showed that Orb protein was undetectable in or $b^{\text {dec }}$ ovaries (Lantz et al., this issue).

Generation of a weak orb allele, orb ${ }^{\mathrm{mel}}$

Transposase-induced mobilization (Cooley et al. 1988) was used to produce additional orb alleles from the or $b^{d e c}$ allele. Most of these produced phenotypes that were similar to the or $b^{d e c}$ phenotype or slightly weaker, like that described by Lantz et al. (1994) for the orb $b^{F 303}$ allele. However one allele, or $b^{m e l}$, which produces a weaker phenotype than orb ${ }^{\text {dec }}$, was particularly informative with regard to the function of orb and is the focus of the remainder of this paper.

or $b^{m e 1}$ fails to complement strong orb alleles, producing ovarian morphologies that are intermediate in phenotype between the strong phenotype (see or $b^{\text {dec }}$ ) and a weak maternal-effect phenotype (see below). Therefore, we conclude that or $b^{\text {mel }}$ acts as a recessive partial lossof-function allele.

Southern blot analysis of $o r b^{m e 1}$ showed that the excision event removed the entire transposon as well as $\sim 500$ bp of orb genomic DNA. We sequenced the or $b^{\text {mel }}$ $5^{\prime}$ UTR and determined that the $5^{\prime}$ breakpoint of the deletion was located at the precise site of transposon insertion in the or ${ }^{d e c}$ allele and that the deletion extended into intron 2, removing the $5^{\prime}$ splice donor site (Fig. 2A). Comparison of cDNA sequence data from or $b^{m e l}$ mutant flies to the wild-type or $b$ cDNA sequence (Lantz et al. 1992) showed that the orb ${ }^{\text {mel }}$ deletion resulted in a complete loss of exon $2(+302$ to $+800 \mathrm{nu}-$ cleotides) from the $o r b^{m e l}$ mRNA; thus, exon 1 is spliced directly to exon 3. Such exon skipping is consistent with the exon definition model for RNA splicing proposed by Berget and colleagues, in which the intact exon /with its $3^{\prime}$ and $5^{\prime}$ splice sites) is the unit of assembly for splicing factors (Robberson et al. 1990; Talerico and Berget 1990). 


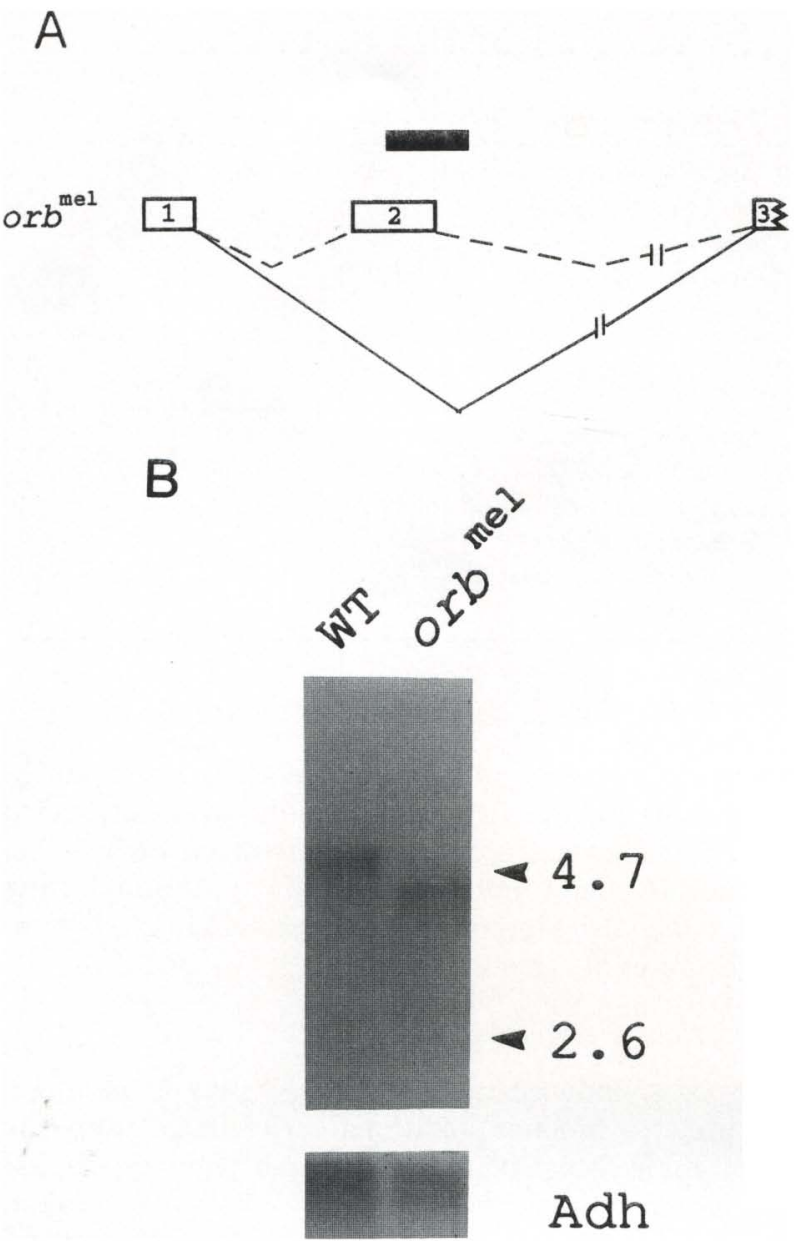

Figure 2. Molecular analysis of the or $b^{\text {mel }}$ allele. $(A)$ Schematic representation of $5^{\prime}$ portion of the orb gene. The or $b^{\text {mel }}$ deletion (solid rectangle) removes 300 bp of $5^{\prime}$ UTR in exon 2 and $\sim 200$ bp of adjacent intron sequence. This deletion interferes with normal splicing (broken lines) of orb transcript, producing $o r b^{\text {mel }}$ mRNA that is missing exon 2 altogether $\mid o r b^{\text {mel }}$ splicing is depicted by solid lines). Open boxes represent exons. $(B)$ Northern blot analysis of $o r b^{m e l}$ mRNA. The autoradiograph shows that $o r b^{\text {mel }}$ transcript migrates at a position $\sim 500$ nucleotides shorter than wild-type (WT) orb transcript. Both lanes contain $\sim 2 \mu \mathrm{g}$ of ovarian poly $(\mathrm{A})^{+} \mathrm{RNA}$ hybridized with a portion of the orb cDNA. Hybridization to $A d h$ (Goldberg 1980) is shown as a control for RNA loading.

Northern analysis revealed that the transcript produced by or $b^{m e l}$ is smaller than wild-type orb mRNA by $\sim 500$ nucleotides, as predicted by the sequence data, and is present at approximately wild-type levels (Fig. 2B).

orb $^{\text {mel }}$ eggs display $D / V$ defects

In females that are homozygous for the or $b^{m e l}$ mutation, the morphology of structures on the dorsal side of the eggshell is aberrant. The most striking aspect of these defects is the fusion or absence of the two respiratory appendages, called dorsal appendages, that normally arise from the dorsolateral anterior surface of the egg (Fig. 3). Similar eggshell defects have been described for grk, top/DER, cni, rho, and brn mutations, which block dorsal follicle cell fate determination and produce eggshells referred to as ventralized (Schüpbach 1987; Ashburner et al. 1990; Schüpbach et al. 1991; Goode et al. 1992; Ruohola-Baker et al. 1993). As shown in Table 2, $23 \%$ of the eggs produced by or $b^{\text {mel }} / o r b^{\text {mel }}$ females displayed fused dorsal appendages and $6 \%$ lacked both dorsal appendages. These effects were enhanced when the amount of orb gene product was reduced by placing orb $^{\text {mel }}$ in trans to or $b^{\text {dec }}$ (data not shown). However, because $o r b^{\text {mel }}$ was derived from the or $b^{\text {dec }}$ chromosome, we were concerned that noncomplementing background mutations might contribute to these effects. Therefore, in the following experiments we have used a different strong loss-of-function allele, or $b^{F 343}$, an ethylmethane sulfonate-induced mutation identified as an orb allele by its failure to complement $o r b^{d e c}$ (Lantz et al., this issue).
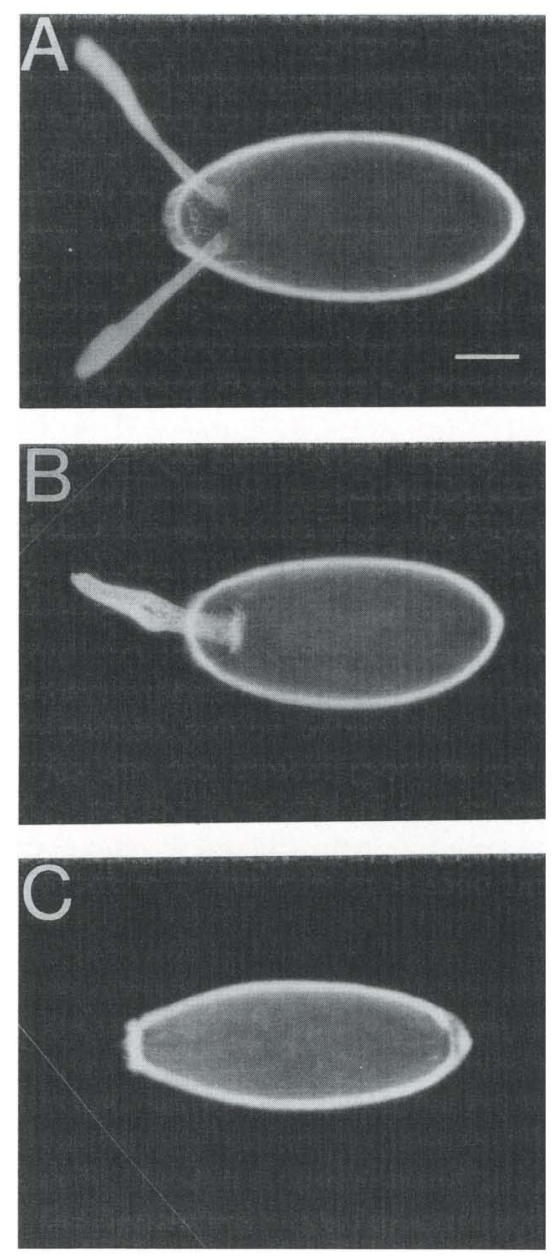

Figure 3. or $b^{m e l}$ eggshells display a reduction of dorsal structures. $(A)$ Wild-type eggshell. Two respiratory appendages extend from the dorsolateral anterior surface. Anterior is left. Bar, $100 \mu \mathrm{m}$ (applies to all panels). $(B, C)$ orb $^{\mathrm{mel}}$ eggshells. Dorsal appendage material is fused and originates at the dorsal midline $(B)$ or is missing $(C)$. 
Table 2. Maternal-effect lethal eggshell phenotypes of orb $^{\mathrm{mel}}$ females

\begin{tabular}{|c|c|c|c|c|}
\hline \multirow[b]{2}{*}{ Genotype } & \multirow[b]{2}{*}{ Number ${ }^{a}$} & \multicolumn{3}{|c|}{ Percentage } \\
\hline & & $\begin{array}{l}\text { fused dorsal } \\
\text { appendages }\end{array}$ & $\begin{array}{l}\text { lacking dorsal } \\
\text { appendages }\end{array}$ & $\begin{array}{l}\text { two dorsal } \\
\text { appendages }\end{array}$ \\
\hline \multicolumn{5}{|l|}{ Controls } \\
\hline$o r b^{F 343} / T M 3$ & 237 & $<1$ & 0 & $>99$ \\
\hline $\begin{array}{l}\text { orb } b^{\text {mel }} / T M 3 \\
\text { orb mutants }\end{array}$ & 263 & $<1$ & $<1$ & $>99$ \\
\hline$o r b^{m e l} / o r b^{m e l}$ & 556 & 23 & 6 & 71 \\
\hline orb $^{\text {mel }} / o r b^{F 343}$ & 1437 & 21 & 78 & $<1$ \\
\hline
\end{tabular}

Fused dorsal appendage phenotype ranges from fusion at base of appendages to fusion along entire length of appendage.

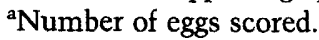

Of the eggs produced by orb $b^{m e 1} /$ orb $^{F 343}$ females, $21 \%$ displayed fused dorsal appendages and $78 \%$ were missing both dorsal appendages (Table 2). These data indicate that dorsal appendage formation is sensitive to the dose of or $b^{+}$activity.

A significant fraction of $o r b^{m e l} / o r b^{F 343}$ eggs are approximately one-half to three-fourths of the normal egg length (data not shown). Consistent with this observation, we frequently see smaller-than-normal late-stage or $b^{\text {mel }} /$ or $b^{F 343}$ oocytes, the apparent result of the incomplete transfer of nurse cell contents into the oocyte; this phenotype is similar to that described for kelch and chickadee mutants (Schüpbach and Wieschaus 1991; Cooley et al. 1992; Xue and Cooley 1993). In addition, we have observed that the follicle cells surrounding these smaller-than-normal orb $b^{\text {mel }} /$ or $b^{F 343}$ oocytes appear more columnar in shape than wild type (e.g., see Fig. 6D, below). Although the cause of this altered follicle cell morphology is presently unknown, we suspect that it may be a consequence of the reduced surface area that these smaller oocytes provide.

orb interacts genetically with grk and top/DER

Because eggshells of orb $^{\text {mel }}$ females showed defects similar in many respects to those produced by grk, top/DER, and cni mutations, we tested for genetic synergism between these mutations and orb by constructing double heterozygous females (Table 3). The alleles used for these genetic complementation tests are described in Table 1B. Examination of eggs produced by $\mathrm{grk}^{H K 36} /+\mathrm{fe}-$ males showed that dorsal follicle cell determination was sensitive to the dose of $g r k$ alone, as a reproducible percentage of eggshells carried fused dorsal appendages (Table 3). Evidence for this incompletely penetrant dominant effect of grk mutations has been obtained independently (Forlani et al. 1993; T. Schüpbach, pers. comm.). Remarkably, $82 \%$ of the eggs laid by females doubly heterozygous for orb $b^{F 343}$ and $g r k^{H K 36}$ carried fused dorsal appendages, whereas $69 \%$ of the eggs laid by females doubly heterozygous for or $b^{F 343}$ and a weaker grk allele, $g_{r k}{ }^{H G 21}$, carried fused dorsal appendages. Similar results were obtained with double heterozygous combinations of $o r b^{d e c}$ and grk alleles. Thus, mutations in orb act as dominant enhancers of the partially dominant effects of grk alleles.

We also tested for genetic synergism with top/DER alleles; these mutations behave as recessive loss-of-function alleles (Schüpbach 1987; Clifford and Schüpbach 1989|. or $b^{F 343}$ fully complemented top ${ }^{1}$, a weak allele; eggshells with single dorsal appendages occurred at background levels $(<1 \%)$ in $\operatorname{top}^{1} /+$; orb $b^{F 343} /+$ ovaries. However, the or $b^{F 343}$ allele displayed dramatic second-site noncomplementation of $t o p^{C O}$, a strong allele, such that $71 \%$ of eggs laid by top $\mathrm{CO} /+$; or $b^{F 343} /+$ females carried single dorsal appendages (Table 3). Similar effects on dorsal appendage formation were observed using or $b^{\text {dec }}$ in place of $o r b^{F 343}$, although the percentage of eggshells with fused dorsal appendages was less than that pro-

Table 3. Percentages of fused dorsal appendages produced by double heterozygotes

\begin{tabular}{|c|c|c|}
\hline Genotype & Number $^{a}$ & $\begin{array}{l}\text { Fused dorsal } \\
\text { appendages }(\%)\end{array}$ \\
\hline \multicolumn{3}{|l|}{ Controls } \\
\hline$o r b^{F 343} / T M 3$ & 237 & $<1$ \\
\hline$o r b^{d e c} / T M 3$ & 414 & $<1$ \\
\hline$g r k^{H K 36} /+; T M 3 /+$ & 265 & 13 \\
\hline $\operatorname{grk}^{H G 21 /+; T M 3 /+}$ & 414 & 2 \\
\hline top $\mathrm{CO} /+; T M 3 /+$ & 144 & 1 \\
\hline $\mathrm{cni}^{A A 12} /+; T M 3 /+$ & 320 & 0 \\
\hline K10 ${ }^{L M O O} /+; T M 3 /+$ & 167 & 0 \\
\hline \multicolumn{3}{|l|}{ Double heterozygotes } \\
\hline$g_{r k} k^{H K 36} /+;$ orb $b^{F 343} /+$ & 262 & 82 \\
\hline$g r k^{H K 36} /+;$ orb $b^{d e c} /+$ & 230 & 57 \\
\hline$g k^{H G 21} /+; o r b^{F 343} /+$ & 240 & 69 \\
\hline$g r k^{H G 21} /+; o r b^{d e c} /+$ & 283 & 11 \\
\hline top $\mathrm{p}^{\mathrm{CO}} /+;$ orb $b^{F 343} /+$ & 218 & 71 \\
\hline top $\mathrm{CO} /+;$ orb $^{d e c} /+$ & 227 & 6 \\
\hline $\mathrm{cni}^{A A 12} /+;$ orb $^{F 343} /+$ & 340 & 2 \\
\hline$K 10^{L M O O} /+;$ orb $b^{F 343 /+}$ & 280 & 6 \\
\hline$g_{r k} \mathrm{H}^{H K 36}+1+t o p^{C O}$ & 424 & 90 \\
\hline
\end{tabular}

Fused dorsal appendage phenotype ranges from fusion at base to fusion along entire length of appendage. Eggshells with fused dorsal appendages represent the most severe phenotype produced by these double heterozygotes.

a Number of eggs scored. 
duced with or $b^{F 343}$. In contrast, eggshells produced by females doubly heterozygous for a strong cni allele, $c n i^{A A 12}$, and $o r b^{F 343}$ showed very weak effects on dorsal appendage formation.

Finally, as predicted by the synergisms described above, grk and top/DER alleles interact genetically as trans-heterozygotes: $90 \%$ of the eggshells produced by females doubly heterozygous for $g r k^{H K 36}$ and $t o p^{C O}$ displayed fused dorsal appendages. Similar genetic interactions between grk and top/DER mutations have been observed by T. Schüpbach (pers. comm.).

To test orb for potential genetic interactions with genes of the dorsalizing class of eggshell mutations, we constructed females that were doubly heterozygous for $K 10^{L M O O}$ (Table 1B) and or ${ }^{F 343}$. A small but reproducible percentage of these eggshells carried fused dorsal appendages, suggesting at best only weak genetic interaction (Table 3).

\section{The distribution of grk mRNA is disrupted in orb mutant oocytes}

Phenotypic interactions between mutations at genetically unlinked loci have successfully identified genes that function in biochemically related pathways /Cline 1988; Regan and Fuller 1990; Hoffmann 1991; Rubin 1991). The genetic interactions between orb, grk, and top/DER suggested that orb might function in the pathway of dorsalizing signal production. Recently, NeumanSilberberg and Schüpbach (1993) have shown that grk mRNA is localized within the oocyte and that this localization is disnupted by mutations known to affect the D/V pattern of the eggshell and embryo. They postulate that grk mRNA localization is important for spatially restricting the dorsalizing ligand that asymmetrically activates the top/DER receptor in follicle cells. The cytoplasmic distribution of Orb protein (Lantz et al., this issue; see below) and the potential RNA-binding domains in the Orb protein sequence (Lantz et al. 1992) made it a candidate for involvement in mRNA localizations. Therefore, we examined grk transcript distribution in egg chambers from orb $b^{\text {mel }} / o r b^{F 343}$ females.

Localization of the grk mRNA in mutant egg chambers from the germarium to stage 7 was normal (data not shown). However, beginning at stages $8-9$, the localization pattern of $g r k$ mRNA was altered. Rather than being tightly restricted to the dorsal side of the oocyte nucleus as in wild type (Fig. 4A), the grk transcript was distributed across the entire anterior end of the mutant oocyte (Fig. 4B). Interestingly, this pattern of grk mRNA distribution is similar to that observed for $f_{s}(1) \mathrm{K} 10$ and $s q d$ mutations, which dorsalize the eggshell, as well as capu and spir mutations, which produce both dorsalized and ventralized eggshells (Manseau and Schüpbach 1989; L. Manseau, pers. comm.). The potential significance of these results for the production of the dorsalizing signal will be discussed later.

\section{$D / V$ polarity defects extend to orb mutant embryos}

Most mutations that affect the polarity of the eggshell

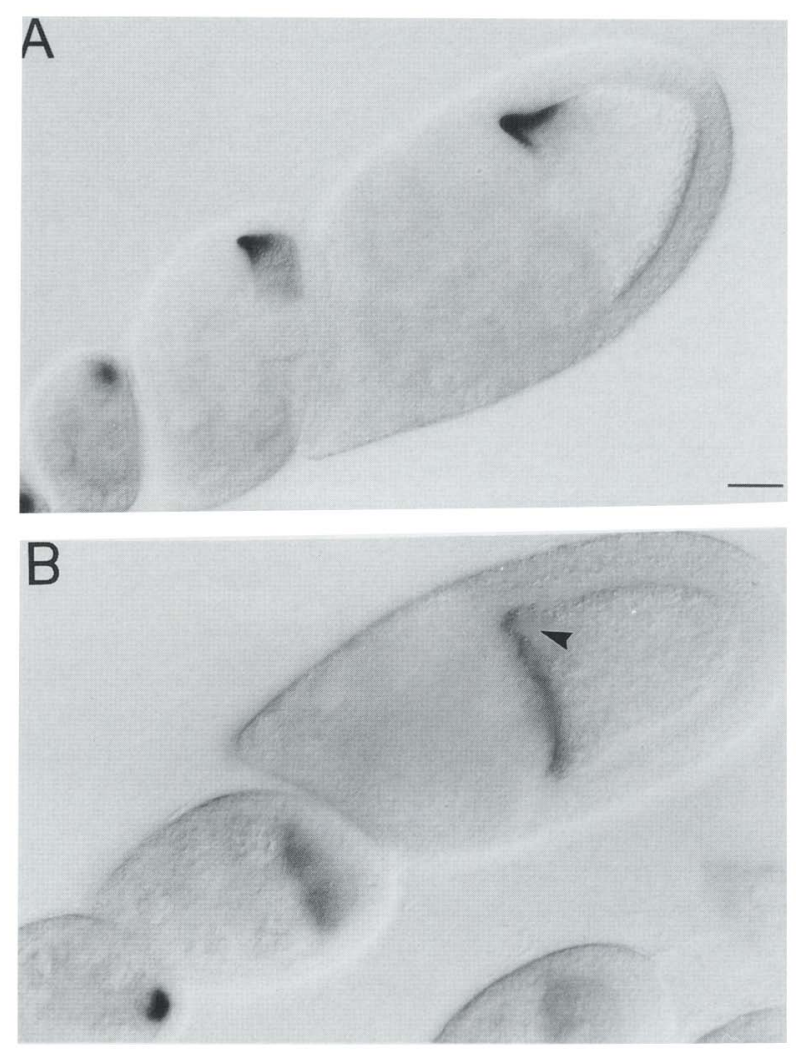

Figure 4. grk mRNA is mislocalized in late-stage orb $b^{m e l} /$ orb $^{F 343}$ oocytes. (A) Detection of grk mRNA distribution by in situ hybridization in stages 6,8 , and 9 wild-type egg chambers (lateral view). In the late stages of oogenesis, grk transcript is detected in the dorsal corner of the oocyte (see also NeumannSilberberg and Schüpbach 1993). Bar, $25 \mu \mathrm{m}$ (applies to both panels). $(B) \mathrm{orb}^{\mathrm{mel}} / \mathrm{or} \mathrm{b}^{\mathrm{F343}}$; lateral view of stages 6,8 , and $10 \mathrm{egg}$ chambers. In late-stage mutant oocytes, grk mRNA is not restricted to the dorsal corner of the oocyte nucleus (arrowhead) but is distributed along the entire margin of the oocyte anterior end.

also affect the polarity of the embryo (Ashburner et al. 1990; Schüpbach et al. 1991; Kelly 1993; Ruohola-Baker et al. 1993). Because we expected that the reduced dorsal eggshell structures of orb mutant eggs might indicate a reduction of dorsal cell fates (ventralized phenotype) in embryos, we examined the cuticles produced by embryos of both $o r b^{m e l} / o r b^{m e l}$ and orb $b^{m e l} / o r b^{F 343}$ females. We were surprised to find that none of the orb mutant embryonic cuticles displayed any recognizable $D / V$ patterning defects (Table 4).

To check the possibility that the classes of embryos with incomplete or no cuticle (Table 4, i.e., scraps of cuticle and undeveloped classes) might have $D / V$ polarity defects, we analyzed a much earlier indicator of the $\mathrm{D} / \mathrm{V}$ pattern, the ventral-to-dorsal nuclear translocation gradient of the dorsal protein (Steward et al. 1988; Roth et al. 1989; Rushlow et al. 1989; Steward 1989). In wildtype embryos, the dorsal protein is localized in nuclei on the ventral surface, whereas the protein is excluded from nuclei on the dorsal surface (Fig. 5A). Mutations in ma- 
Table 4. Phenotypes of embryos produced by orb $\mathrm{b}^{\mathrm{mel}} / \mathrm{orb}^{\mathrm{mel}}$ and orb $^{\mathrm{mel}} / \mathrm{orb}^{\mathrm{F} 343}$ females

\begin{tabular}{lcc}
\hline & \multicolumn{2}{c}{ Percentage $^{\mathrm{a}}$} \\
\cline { 2 - 3 } Embryonic phenotype & $\begin{array}{c}\mathrm{orb}^{\text {mel}} / o r b^{\text {mel }} \\
(n=201)\end{array}$ & $\begin{array}{c}\text { orb }^{\text {mel }} / \text { orb }^{F 343} \\
(n=322)\end{array}$ \\
\hline Undeveloped & 46 & 67 \\
Scraps of cuticle & 7 & 32 \\
Abdominal segmentation & & \\
$\quad$ defects & 25 & 1 \\
$\quad$ no abdominal segments & 18 & $<1$ \\
$\quad$ few abdominal segments & 5 & 0 \\
$\quad$ fusion of abdominal segments & 2 & $<1$ \\
Wild type & 22 & 0 \\
$\quad$ unhatched & 4 & - \\
$\quad$ hatched & 18 & - \\
\hline
\end{tabular}

Embryos that had arrested prior to cuticle deposition were classified as undeveloped. By this assay, we could not distinguish undeveloped embryos from eggs that were unfertilized (see text). ${ }^{a}(n)$ Number scored.

ternally active genes that are essential for embryonic $\mathrm{D} / \mathrm{V}$ polarity produce shifts in the dorsal protein gradient in a ventral-to-dorsal manner (Roth et al. 1989; Stewart 1989 |. In completely ventralized embryos, dorsal protein is present exclusively in the nuclei around the circumference of the embryo. Partially ventralized embryos display an expansion of dorsal protein nuclear localization toward the dorsal surface.

Because or $b^{m e l} /$ orb $^{F 343}$ eggs showed the highest penetrance of ventralized eggshell defects, we tested these embryos by immunohistochemical detection of nuclear dorsal distribution. In most of the blastoderm-stage $o r b^{m e l} / o r b^{F 343}$ embryos ( $>90 \%$ ), the domain of nuclear dorsal was expanded considerably, indicating an increase in ventral cell fates in the embryo (Fig. 5, cf. A and B). However, in at least half the embryos examined, the pattern of dorsal-positive nuclei was different from that described for embryos ventralized by mutations in other maternal dorsoventral genes such as Toll and top/DER (Roth et al. 1989; Steward 1989). Figure 5C shows an example of this novel dorsal protein distribution. Note that dorsal protein was excluded from nuclei on the ventral surface at the embryo's anterior end and included in nuclei on the dorsal surface at the posterior end. The basis for this pattern of dorsal protein translocation is unknown at this time. Nevertheless, the patterns of dorsal-positive nuclei presented in Figure 5, B and C, both indicate that the active domain of embryonic ventralizing signal is expanded in orb mutant embryos.

\section{Embryos produced by orb ${ }^{\text {mel }}$ females display posterior group defects}

Our analysis of embryonic cuticles (see Table 4) and of $\mathrm{D} / \mathrm{V}$ polarity in embryos produced by orb $\mathrm{rel}^{\mathrm{mel}} / \mathrm{orb}^{\mathrm{F343}} \mathrm{fe}-$ males indicated early developmental disruptions. However, embryos produced by $o r b^{m e l} / o r b^{\text {mel }}$ females (hereafter referred to as or $b^{\text {mel }}$ embryos), which can complete more stages of embryogenesis, revealed another aspect of the orb mutant phenotype and suggested that orb was required for $\mathrm{A} / \mathrm{P}$ axis formation in addition to the requirement described previously for $\mathrm{D} / \mathrm{V}$ patterning. or $b^{m e l}$ embryos displayed abdominal segment deletions and lacked pole cells, defects typical of the posterior class of maternal-effect mutants (for review, see by Lasko 1992; Lehmann 1992; St Johnston and NüssleinVolhard 1992). Twenty-five percent of orb ${ }^{m e l}$ embryonic
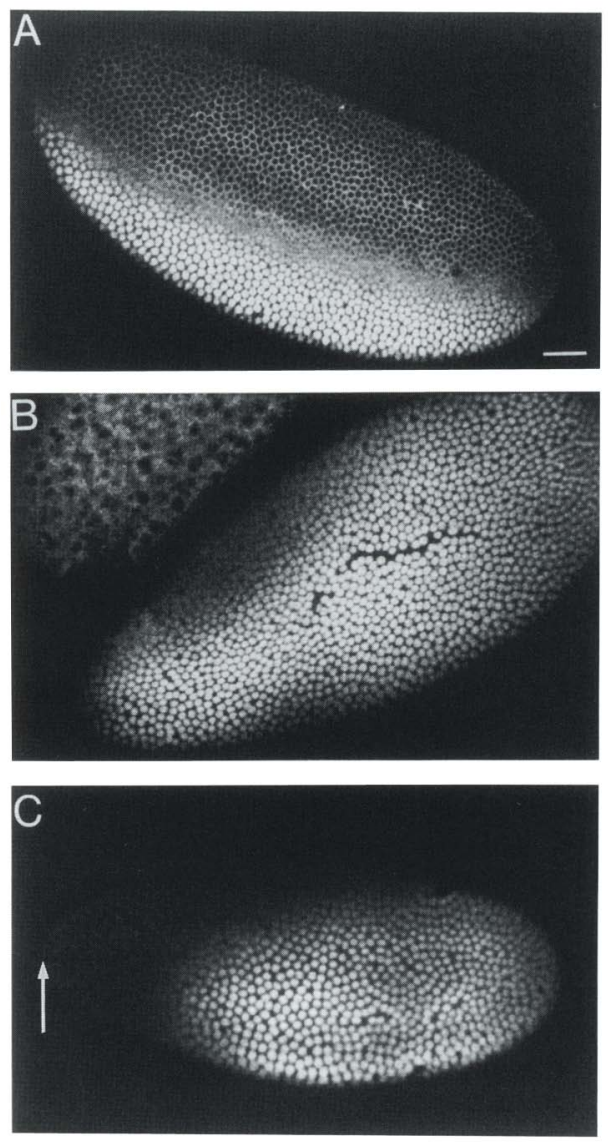

Figure 5. Confocal optical sections of dorsal protein distribution in embryos produced by wild-type and orb ${ }^{\mathrm{mel}} / \mathrm{orb} b^{\mathrm{F} 343} \mathrm{fe}$ males. (A) The dorsal-to-ventral gradient of dorsal protein distribution in a wild-type blastoderm-stage embryo. Nuclei on the ventral surface (lower region of embryo) contain the highest levels of dorsal protein, whereas the protein is excluded from nuclei and present in the cytoplasm on the dorsal surface (upper region of embryo). In the lateral region of the embryo, dorsal protein is distributed equally in the nuclei and cytoplasm, which appears as a diffuse stripe across the length of the embryo. Anterior is left. Bar, $25 \mu \mathrm{m}$ (applies to all panels). $(B, C)$ Pattern of dorsal distribution in blastoderm-stage embryos from $o r b^{m e l} / o r b^{F 343}$ females. The region of nuclear dorsal distribution is expanded $(B)$, indicating an expansion of ventral fates in the embryo. Also frequently observed is a pattern $(C)$ in which the region of cytoplasmic dorsal distribution is shifted toward the anterior portion of the embryo and the region of nuclear dorsal distribution is shifted toward the posterior portion of the embryo. The arrow marks the embryo's anterior end. 
cuticles manifested abdominal segmentation defects (Table 4; Fig. 6, cf. A and B). In a related study, in which developing embryos were observed directly, we found that pole cells were absent in 27 of 33 or $b^{\text {mel }}$ embryos that completed cellularization.

Even though $22 \%$ of or $b^{m e l}$ embryos produced wildtype cuticles, severe defects were observed as well (Table 4). Approximately half of $o r b^{m e l}$ embryos failed to form cuticle (undeveloped), and a small fraction appeared severely aberrant (resembling scraps of cuticle). By comparison, examination of or $b^{\text {mel }} / \mathrm{orb}^{F 343}$ embryos showed that almost none can make wild-type cuticle. Instead, a majority of these embryos failed to deposit cuticle and the remainder formed mostly scraps of cuticle. Thus, both allelic combinations produced classes of arrested embryos that could not be distinquished from eggs that were unfertilized. Therefore, we determined the percentages of unfertilized eggs produced by or $b$ mutant females by performing immunocytochemistry with antibodies that recognized a sperm tail antigen (Karr 1991). We found that $23 \%$ of orb $b^{m e l} /$ orb $b^{m e l}$ eggs $(n=198)$ and $29 \%$ of orb $^{\text {mel }} /$ orb $^{F 343}$ eggs $(n=307)$ failed to become fertilized. Because the numbers of unfertilized eggs can account for only half of the undeveloped embryos observed (see Table 4), we conclude that some of the orb mutant embryos arrest early in embryogenesis. We suspect that these undeveloped embryos and those that produce scraps of cuticle result from the simultaneous disruption of several developmental processes that are sensitive to the amount of functional orb gene product. orb mutants fail to localize osk $m R N A$ at the posterior pole of the oocyte

Because proper pole cell formation and abdominal segmentation require the localization of osk mRNA to the posterior pole of the oocyte (Ephrussi et al. 1991; Kim-Ha et al. 1991), we examined the distribution of osk mRNA in the egg chambers of $o r b^{m e l} / o r b^{F 343}$ females. In wildtype egg chambers, osk mRNA is present in the nurse cells and is localized at the posterior pole of the oocyte during late oogenesis (Ephrussi et al. 1991; Kim-Ha et al. 1991). Figure 6C shows an example of osk mRNA distribution in a wild-type stage 10 egg chamber. In contrast, posterior osk mRNA localization was never observed in orb $b^{\text {mel }} / o r b^{F 343}$ oocytes. Rather, osk mRNA was detected throughout the oocyte cytoplasm, with some enrichment in the peripheral regions of the oocyte (Fig. 6D). Localization of osk mRNA to the oocyte appeared normal for egg chambers from germarium through stage 7 in or $b^{\text {mel}} /$ orb $^{F 343}$ ovaries (Fig. 6, cf. E and F).

\section{bcd and $\mathrm{fs}(1) \mathrm{K} 10 \mathrm{mRNA}$ localization in the orb mutant}

To this point, the phenotypic consequences of the orb mutation had predicted successfully that grk and osk mRNA localizations were or $b$ dependent. To determine whether or $b$ was required for general mRNA localization in the oocyte, we examined the pattern of two other well-characterized transcript localizations, bcd and
Figure 6. Embryos of orb mutant females display abdominal segment deletions and fail to localize osk mRNA to the posterior pole of the oocyte. (A) Wild-type embryonic cuticle, showing distinct denticle bands over each abdominal segment. Anterior is left and dorsal is up. Bar, $100 \mu \mathrm{m}$ (applies to $A$ and $B$ ). (B) Representative posterior group phenotype of embryonic cuticles produced by or $b^{\text {mel }}$ mutant mothers. $\mathrm{Ab}$ dominal segments are absent. $(C)$ Detection of osk mRNA by in situ hybridization in a wildtype stage 10 egg chamber. osk mRNA is detected in the nurse cells (left) and is localized within the oocyte to the posterior pole as a tight band (arrow; see also Ephrussi et al. 1991; KimHa et al. 1991). Anterior is left. Bar, $25 \mu \mathrm{m}$ (applies to $C$ and $D)$. $(D)$ orb $^{\text {mel }} /$ orb $b^{F 343}$ egg chamber (stage 10). osk mRNA is detected in the nurse cells and throughout the oocyte and never becomes concentrated at the oocyte posterior pole. Some enrichment of osk mRNA is detected in the cytoplasm that underlies the oocyte cortex. No consistent difference in osk mRNA abundance in the nurse cells has been observed between wild-type and orb mutant egg
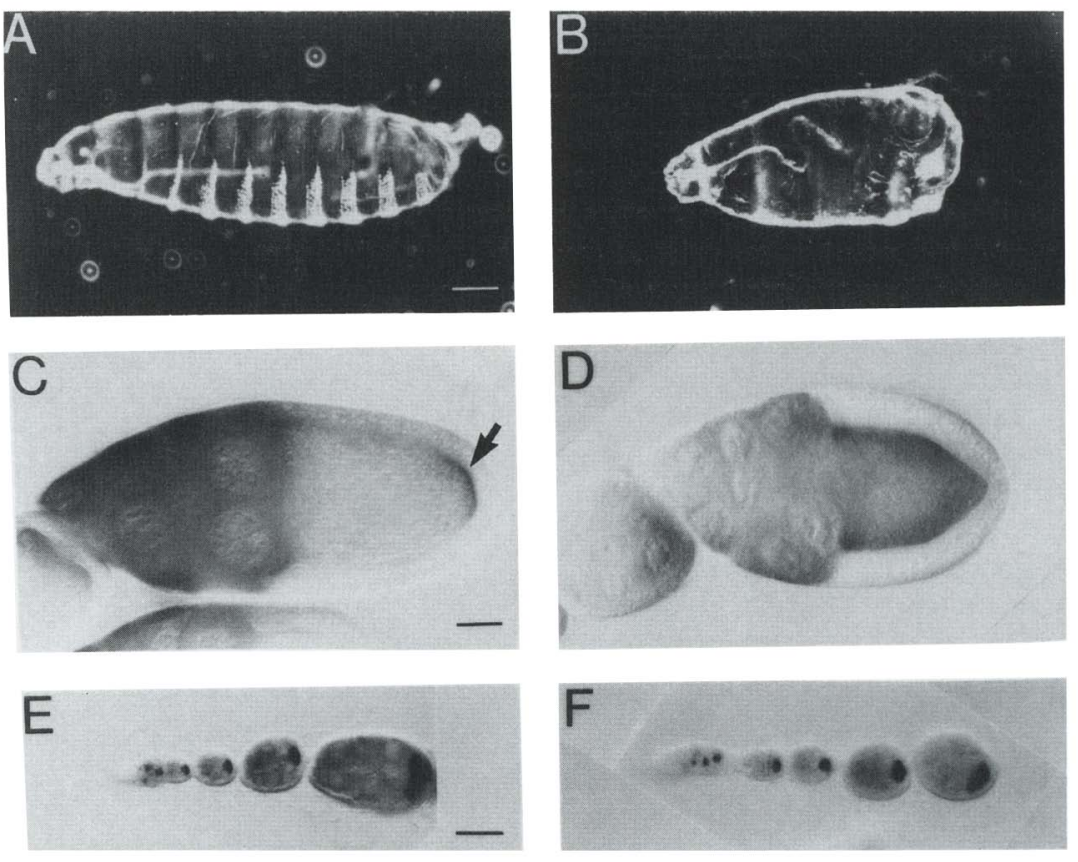
through stage 7). osk mRNA localizes to the oocyte in each egg chamber. Anterior is left. Bar, $50 \mu \mathrm{m}$ (applies to $E$ and $F)$. $(F)$ orb $^{\text {mel }} /$ orb $^{F 343}$ ovariole (germarium through stage 7). osk mRNA localization to the oocyte in each egg chamber appears identical to wild type. Less intense staining observed in $F$ is a consequence of shorter reaction development time than $E$. 
$f s(1) K 10$ (Haenlin et al. 1987; Berleth et al. 1988; Cheung et al. 1992), in or $b^{\text {mel}} / o r b^{F 343}$ egg chambers. The distribution of $b c d$ and $f_{s}(1) K 10$ transcripts within orb mutant oocytes appeared normal throughout oogenesis. This included the later stages when both $b c d$ and $f_{s}(1) K 10$ transcripts were correctly localized to the anterior end of orb mutant oocytes (Fig. 7, A-D). However, in some cases, $f s(1) K 10$ mRNA localization in orb mutan+ oocytes appeared less tightly restricted to the anteric in of the oocyte (Fig. 7, cf. C and D).

\section{orb $^{\text {mel }}$ mutants produce an aberrantly localized protein}

In wild-type ovaries, Orb protein is distributed in a dynamic and specific pattern during oogenesis (Lantz et al., this issue). Especially significant for the phenotypes produced by the or $b^{m e l}$ allele is the observation that Orb protein is associated with the cortex of the oocyte and is enriched at the anterior corners and the posterior pole of the oocyte during stage $8-10$ (Fig. 8A; see also Lantz et al., this issue). In light of the orb-dependent localization of transcripts to the oocyte dorsal-anterior and posterior ends, we investigated the distribution of Orb protein in or $b^{\text {mel }} /$ or $b^{F 343}$ egg chambers.

Before stage 8 , the accumulation of Orb protein in

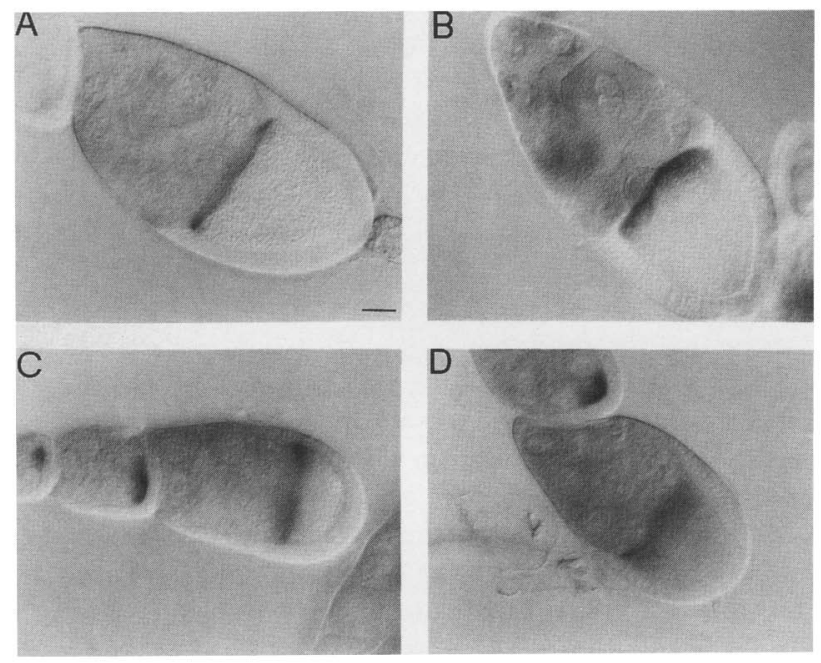

Figure 7. $b c d$ and $K 10 \mathrm{mRNA}$ anterior localization in latestage $o r b^{\text {mel }} / o r b^{F 343}$ egg chambers. $(A)$ Detection of wild-type bcd mRNA by in situ hybridization in a wild-type stage $10 \mathrm{egg}$ chamber. $b c d$ mRNA is detected along the anterior margin of the oocyte (see also Berleth et al. 1988). Bar, $25 \mu \mathrm{m}$ (applies to all panels). Anterior is left. $(B)$ orb $b^{\text {mel }} /$ orb $^{F 343}$ egg chamber (stage 10). bcd mRNA is correctly localized to the anterior margin of the oocyte. $(C)$ Detection of $f_{s}(1) K 10$ mRNA by in situ hybridization in a wild-type stage 9 egg chamber. $f_{s}(1) K 10$ mRNA is detected at the anterior end of the oocyte as a tight band (see also Haenlin et al. 1987; Cheung et al. 1992). (D) orb $b^{\text {mel }} /$ orb $b^{F 343}$ egg chamber (stage 9). fs(1)K10 mRNA correctly localizes along the anterior margin of the oocyte. This micrograph shows an example of the lower efficiency of $f_{s}(1) K 10$ mRNA localization observed in some mutant oocytes (see text).
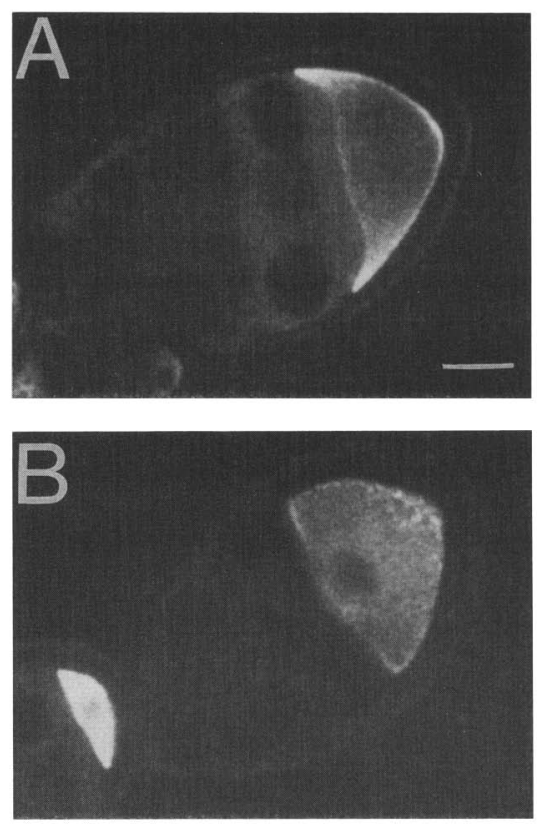

Figure 8. Confocal optical sections of Orb protein distribution in wild-type and $o r b^{\text {mel }} / o r b^{F 343}$ stage 9 egg chambers. $(A) \mathrm{Im}$ munolocalization of Orb protein in a wild-type stage $9 \mathrm{egg}$ chamber. Orb protein is enriched in the cortical region that underlies the oocyte plasma membrane and especially in the anterior corners and at the posterior pole of the oocyte. The cytoplasm of the nurse cells closest to the oocyte contains higher levels of Orb protein than the cytoplasm of the remaining nurse cells (see also Lantz et al. 1994). Bar, $25 \mu \mathrm{m}$ (applies to

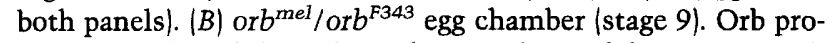
tein is distributed throughout the cytoplasm of the oocyte, with regions in which the protein appears punctate. The levels of Orb protein in the nurse cells closest to the oocyte appear reduced.

oocytes of orb $b^{m e l} /$ orb $b^{F 343}$ egg chambers appeared indistinguishable from wild type (data not shown). However, beginning at stage 8 , and especially evident during stage 9 , Orb protein distribution in these oocytes was aberrant. In stage $9 \mathrm{orb}^{\mathrm{mel}} / \mathrm{orb} \mathrm{b}^{\mathrm{F343}}$ oocytes, Orb was distributed in a diffuse pattern across the oocyte and never became concentrated at the anterior, posterior, or cortical regions of the oocyte (Fig. 8B). In addition, in some areas, the protein appeared punctate instead of homogeneous. These punctate areas may represent regions of protein aggregation, but the nature of such aggregation sites is unknown. Finally, the level of Orb in the nurse cells of stages 8-10 orb $\mathrm{omel}^{\mathrm{m}} / \mathrm{orb}^{F 343}$ egg chambers appeared lower than that of wild type.

\section{Discussion}

\section{orb function during oocyte polarization}

In this paper we present evidence that orb is required for both $\mathrm{A} / \mathrm{P}$ and $\mathrm{D} / \mathrm{V}$ patterning in the eggshell and embryo. We also show that the distribution of at least two transcripts, namely osk and grk, whose localization is apparently critical for formation of these axes and orb 
dependent during stage $8-10$ of oogenesis. During these stages, the oocyte cytoplasm becomes considerably reorganized (Theurkauf et al. 1992) and shows signs of polarization (e.g., the asymmetric distribution of mRNAs) into $\mathrm{D} / \mathrm{V}$ and $\mathrm{A} / \mathrm{P}$ axes (St Johnston and Nüsslein-Volhard 1992; Neuman-Silberberg and Schüpbach 1993). The similarity of Orb protein to RNA-binding proteins (Lantz et al. 1992) and the enrichment of Orb in the anterior and posterior regions of the oocyte cytoplasm during the mid- and late stages of oogenesis (Lantz et al., this issue; see Fig. 8A) are consistent with a role for orb in localizing asymmetrically distributed mRNAs during stage 8-10 of oogenesis.

Because orb clearly has a role during early oogenesis, could the apparent mislocalization of transcripts during stage $8-10$ be a consequence of earlier requirements for or $b$ function? For example, might the loss of or b-dependent activities during earlier oogenesis disrupt egg chamber polarity to such an extent that the subsequent oocyte axes do not form? Although our data do not exclude this possibility, a considerable amount of evidence supports a function for or $b$ beyond the early egg chamber. First, the morphology of $o r b^{m e l} / o r b^{F 343}$ egg chambers displays normal polarity (see Fig. 4B). The oocyte occupies its usual posterior position in the egg chamber, and the follicle cells execute their normal posterior-ward migrations to surround the oocyte. Second, no indication of early disruptions (prior to stage 8 ) in the distribution of oocyte-specific mRNAs [osk, grk, bcd, and $\left.f_{S}(1) K 10\right]$ can be detected in $o r b^{\text {mel} / o r ~} b^{F 343}$ egg chambers, suggesting that polarity in the egg chamber is intact. Third, the genetic synergism displayed between orb and grk (see Table 3 ) is most consistent with a role for orb during the time that the dorsalizing signal is passed from the oocyte to the overlying follicle cells. This signaling event is estimated to begin during stage 8 or 9 , based on the timing of the movement of the oocyte nucleus to the future dorsal corner of the oocyte (Schüpbach et al. 1991), studies of the stages in which laser ablation of the oocyte nucleus can phenocopy the ventralized phenotype (Montell et al. 1991), and the redistribution of grk mRNA to the dorsal anterior corner during these stages (NeumanSilberberg and Schüpbach 1993). Therefore, we postulate that orb is required specifically during stage $8-10$ of oogenesis for the localization of transcripts.

\section{Linkage between $A / P$ and $D / V$ polarity systems}

Unlike most of the genes that can produce a reduction in the dorsal surfaces of the eggshell and embryo, mutation of orb also disrupts A/P axis formation /see Figs. 3 and 6; Tables 2 and 4). A functional oocyte nucleus (Montell et al. 1991) and the genes capu and spir are also required for the proper formation of both axes (Manseau and Schüpbach 1989). Mutations in capu and spir result in both ventralized and dorsalized eggshells as well as embryos that display $\mathrm{D} / \mathrm{V}$ patterning and posterior group defects (Manseau and Schüpbach 1989; L. Manseau, pers. comm.). Manseau and Schüpbach (1989) addressed such effects on both polarity systems by speculating that capu and spir function as cytoskeletal elements that organize cytoplasm or move molecules within cytoplasm. Our results suggest that the mechanisms of mRNA localization link $\mathrm{A} / \mathrm{P}$ and $\mathrm{D} / \mathrm{V}$ axes formation during oogenesis. Because orb mutations disrupt both axes, Orb is probably insufficient by itself to specify the address of a particular transcript. Rather, a role as an RNA-binding component of a larger complex that shuttles transcripts to specific sites seems more plausible.

\section{Involvement in dorsal follicle cell determination}

The genetic synergism displayed by double heterozygous combinations of orb and grk or orb and top/DER mutations (see Table 3 ) suggests that these genes might contribute to the same developmental pathway. Such tests for second-site noncomplementation or dominant enhancement have been useful for revealing interactions among genes mutable to similar phenotypes, as well as for the isolation of new mutations in genes acting in related pathways (Botas et al. 1982; Dambly-Chaudière et al. 1988; Torres and Sánchez 1989). We propose that or $b$, together with other maternal $\mathrm{D} / \mathrm{V}$ genes including $g r k$ and top $/ D E R$, is required for proper communication between the germ line and follicle cells to signal dorsal follicle cell fates.

Recently, Neumann-Silberberg and Schüpbach (1993) provided an elegant model for how localization of the grk transcript might establish the spatially restricted dorsalizing signal. Our finding that grk mRNA localization is dependent on $o r b^{+}$function provides an explanation for why eggshell polarity is disrupted in orb mutants and why dosage-sensitive genetic interactions exist between orb and grk or top/DER. Noting that these double heterozygotes produced eggshells that resembled those produced by loss-of-function grk or top/DER alleles, we hypothesize that a decrease in orb dosage in $o r b /+; g r k /+$ egg chambers produces a subthreshold level of grk mRNA in the dorsal anterior region of the oocyte, decreasing the amount of dorsalizing signal in that region and resulting in a reduction of dorsal follicle cell fates. Likewise, in orb/+; top/ + egg chambers, a decrease in top/DER expression in the follicle cells may reduce their sensitivity to the dorsalizing signal when combined with a subthreshold level of localized grk caused by the orb mutation. The fact that double heterozygous combinations of $g r k$ and top/DER loss-of-function alleles produce similar reductions in dorsal eggshell structures /see Table 3 ) is consistent with this explanation.

It is worth noting that the effects of orb (see Fig. 4B) and $f_{s}(1) K 10$ mutations (Neuman-Silberberg and Schüpbach 1993) on grk transcripts may not be limited to localization alone, as orb and $f_{s}(1) K 10$ mutants fail to localize grk mRNA in similar ways yet produce largely opposite phenotypes. Other factors, such as effects on abundance or translational efficiency of grk mRNA, might influence the final phenotypic consequences. In fact, Neumann-Silberberg and Schüpbach (1993) noted that the abundance of grk mRNA might be reduced in capu and spir mutants compared with the level of grk 
transcript found in $f_{s}(1) K 10$ mutant egg chambers. The production of both dorsalized and ventralized phenotypes in eggshells and embryos mutant for capu and spir (Manseau and Schüpbach 1989; L. Manseau, pers. comm.) suggests that the intensity of the dorsalizing signal might be influenced by several factors.

\section{A model for orb function in osk mRNA localization}

The fact that osk mRNA localization to the oocyte posterior end is orb dependent is sufficient to explain the posterior group defects observed in orb ${ }^{\text {mel }}$ embryos (see Fig. $6 \mathrm{~B}$; Table 4). How might orb regulate osk mRNA distribution? One possibility is that Orb protein acts as a docking site for osk mRNA at the posterior pole of the oocyte, where it might maintain posterior osk mRNA localization. The posterior enrichment of Orb protein during the stages when osk mRNA is posteriorly localized is consistent with such a role. However, this explanation is weakened by the observation that osk mRNA does not become transiently localized at the posterior pole in orb mutant oocytes. In contrast, such transient localization at the posterior pole has been associated with some mutant alleles of osk (Ephrussi et al. 1991).

A second possibility is that Orb is involved in osk mRNA transport within the egg chamber. Evidence from several laboratories suggests that osk mRNA distribution can be divided into several phases (Ephrussi et al. 1991; Kim-Ha et al. 1991, 1993; St Johnston et al. 1991). First, osk mRNA is transported to the oocyte from its principal site of synthesis in the nurse cells. Second, osk mRNA is transported to the posterior pole of the oocyte. In fact, recently reported experiments have identified several elements in the osk 3' UTR that affect different steps of this process (Kim-Ha et al. 1993). Such stepwise localization may explain why osk mRNA distribution in the oocyte requires the activities of several genes [Bicaudal-D (Bic-D), egalitarian, staufen, capu, and spir; Ephrussi et al. 1991; Kim-Ha et al. 1991; St Johnston et al. 1991) as well as orb. St Johnston et al. (1991) have postulated that Staufen protein, which contains a double-stranded RNA-binding domain (St Johnston et al. 1992; Gatignol et al. 1993), and osk mRNA are localized to the posterior pole as part of a complex. The fact that osk mRNA localization is also orb dependent leads us to postulate that both Orb and Staufen might be part of a multiprotein complex that binds to osk mRNA and transports the mRNA to the oocyte posterior pole via the cytoskeleton. In this case, the distribution of Orb protein could reflect its relative abundance along the routes of transport. Experiments that test direct binding of Orb protein to osk mRNA are in progress.

\section{An early requirement for orb in oogenesis}

Phenotypic analysis of $o r b^{d e c}$ indicates an early requirement for orb in oogenesis (Fig. 1C,E; Lantz et al. 1994). Because intact 16-cell clusters are seldom observed in $o r b^{d e c}$ germaria, the cysts apparently begin to degenerate almost as soon as they form. Considerable evidence sug- gests that several mRNAs accumulate in the presumptive oocyte of the young cysts (Suter et al. 1989; Ephrussi et al. 1991; Kim-Ha et al. 1991; Cheung et al. 1992; Dalby and Glover 1992; Lantz et al. 1992; Yue and Spradling 1992|, either in response to oocyte determination or as part of the actual mechanism of oocyte determination. Thus, RNA-binding proteins are probably active during formation of the germ-line cyst. Analysis of oocyte-specific mRNA localization in or $b^{F 303}$ mutant ovaries, which display a slightly weaker phenotype than $o r b^{d e c}$, has shown that both Bic-D and $f_{s}(1) K 10$ mRNAs fail to become localized (Lantz et al., this issue). Considering that orb activity is essential for mRNA localization late in oogenesis, we speculate that the loss of orb-dependent mRNA localization in the 16-cell cluster might be so catastrophic that degeneration ensues.

\section{Materials and methods}

Fly stocks

All fly stocks were maintained under standard culturing conditions. $y$; $r y^{506}$ and $w^{118}$ stocks were used as wild-type controls. K10 LMOO is described by Cheung et al. (1992). The balancer chromosome TM3 is described by Lindsley and Zimm (1992).

\section{Generation of orb mutant alleles}

The original P-allele of orb (or $b^{\text {dec }}$ ) was identified as a female sterile mutation by D. Stern and A. Spradling (pers. comm.) and was produced by standard procedures (Spradling 1993b). orb dec carries a transposon insertion containing a lacZ gene (Hiromi et al. 1985). The source of transposase for the transposase-induced reversion of $o r b^{d e c}$ was $P\left(r y^{+} \Delta 2-3\right.$ )(99B) (Robertson et al. 1988).

\section{Microscopy}

Microscopy was performed on a Zeiss Axiophot microscope equipped with phase and differential interference contrast objectives. Confocal images were collected using the MRC 600 system (Bio-Rad Microsciences Division) attached to a Zeiss Axioplan microscope. Confocal images were photographed using a Polaroid FreezeFrame Video Recorder. To examine the cytology of ovaries, tissue was dissected in $1 \times$ PBS $(130 \mathrm{mM}$ sodium chloride, $3 \mathrm{~mm}$ monobasic sodium phosphate, $7 \mathrm{~mm}$ dibasic sodium phosphate) and fixed with $4 \%$ paraformaldehyde in $1 \times$ PBS; ovarioles were then teased apart to expose the egg chambers. Heterozygous or $b^{d e c}$ females from a balanced stock (or $b^{d e c} / T M 3$ ) were used for staining for LacZ activity in ovaries, which was carried out as described by Cooley et al. (1992). F-actin was stained using rhodamine-phalloidin as described by Xue and Cooley (1993).

\section{Nucleic acid hybridization}

Southern blotting procedures and labeling of DNAs by random hexamer priming were as described in Sambrook et al. (1989) and Feinberg and Vogelstein (1984). Hybridizations using DNA probes and subsequent washing protocols were performed at $65^{\circ} \mathrm{C}$ using the procedure of Church and Gilbert as described in Sambrook et al. (1989). 


\section{Cloning of the orb locus}

A 4.5-kb fragment of genomic DNA contiguous with $7.0 \mathrm{~kb}$ of transposon DNA was isolated by plasmid rescue (Pirrotta 1986; Cooley et al. 1988| from orb ${ }^{d e c}$ DNA. A 2.3-kb EcoRI fragment near the site of transposon insertion was used to screen 20,800 colonies of a genomic library supplied by J. Tamkun (Tamkun et al. 1992). Two overlapping genomic clones were recognized as derived from the orb locus by cross-hybridization to phage clones of orb genomic DNA (kindly provided by V. Lantz and P. Schedl, Princeton University, NJ). DNA was sequenced with Sequenase version 2.0 (U.S. Biochemical) according to the manufacturer's instructions. A PCR fragment $1+17$ to +797 nucleotides of orb cDNA) of wild-type genomic DNA was $\sim 1 \mathrm{~kb}$ larger than expected from published or $b \mathrm{cDNA}$ sequence (Lantz et al. 1992). Sequencing this genomic fragment confirmed the presence of an intron at +301 nucleotides of the or $b$ gene.

\section{In situ hybridization and immunocytochemistry}

Whole-mount in situ hybridization to ovaries using either digoxigenin-labeled DNA or RNA probes was performed according to Tautz and Pfeifle (1989) with modifications as follows: After hybridization with digoxigenin-labeled probes in hybridization solution (HS) at $48^{\circ} \mathrm{C}$ (described by McKearin and Spradling 1990), ovaries were washed three times with HS for 15 min each as follows: once in HS and once in HS/PBT (4:1), both at $48^{\circ} \mathrm{C}$; once at room temperature (RT) in $\operatorname{HS} / \mathrm{PBT}(3: 2,2: 3$, and 1:4). After staining, ovaries were washed twice at RT in PBT $(1 \times$ PBS, $0.1 \%$ Tween 20 ) for $15 \mathrm{~min}$ each and then incubated overnight at $4^{\circ} \mathrm{C}$ in anti-digoxigenin antibody conjugated to alkaline phosphatase (AP) (Boehringer Mannheim), 1:2000 in PBT (antidigoxigenin-AP antibodies were first diluted to $1: 100$ in PBT and preincubated with fixed ovaries for $2 \mathrm{hr}$ at RT). Ovaries were mounted onto slides in $25 \%$ glycerol in $1 \times$ PBS. All digoxigenin-labeled probes were synthesized using the Boehringer Mannheim Genius kit by the following methods. RNA probes (for osk hybridization) were prepared as described by Cox et al. (1984). Single-stranded digoxigenin-labeled cDNA probes [for $f_{s}(1) K 10$ hybridization] were prepared using a single primer cycling protocol provided by $\mathrm{N}$. Patel (pers. comm.). Doublestranded digoxigenin-labeled cDNA probes (for bcd and grk hybridizations) were prepared as described by Yue and Spradling (1992). Immunocytochemistry of ovaries was performed using a 1:20 dilution of Orb monoclonal antibody (provided by V. Lantz and P. Schedl), as described by Xue and Cooley (1993), with the exception that the blocking and incubation buffer used consisted of $1 \times \mathrm{PBT}, 1.5 \%$ bovine serum albumin, and $0.5 \%$ Triton $\mathrm{X}-100$. Immunocytochemistry of embryos using either monoclonal antibodies to sperm (Karr 1991) or polyclonal antibodies to dorsal protein (S. Gillespie and S. Wasserman, pers. comm.) was performed as described by Karr et al. (1989) with modifications by S. Gillespie (pers. comm.) using fluorescently labeled secondary antibodies (Jackson Immunoresearch).

\section{Characterization of mutant phenotypes}

Eggshells, embryonic cuticules, and living embryos were prepared and examined as described by Wieschaus and NüssleinVolhard (1986). The presence of pole cells was determined in living embryos between embryonic stages 4 and 6 .

\section{Acknowledgments}

We are grateful to R. Lehmann, P. Macdonald, and R. Cohen for their gifts of plasmids; to T. Karr for providing sperm tail anti- bodies; to S. Gillespie and S. Wasserman for dorsal antibodies; to T. Schüpbach, R. Cohen, S. Roth, V. Lantz, and P. Schedl for sending fly stocks; and to V. Lantz and P. Schedl for providing an orb cDNA clone and Orb monoclonal antibodies. We are especially grateful to V. Lantz, L. Manseau, F. S. Neuman-Silberberg, P. Schedl, and T. Schüpbach for generously sharing unpublished results and reagents. Many thanks go to S. Gillespie for advice on immunocytochemistry, and to S. Gillespie and S. Alexander for assistance in analyzing embryonic phenotypes. We thank C. Hilliard and M. Kuhn for excellent technical assistance. We thank L. Avery, M. Brown, G. Buckles, K. Clark, L. Cooley, F. Katz, B. Ohlstein, A. Spradling, S. Wasserman, and anonymous reviewers for comments on the various drafts of this manuscript. We especially thank L. Cooley, A. Spradling, and S. Wasserman for many helpful discussions. This work was supported by an National Institutes of Health grant GM-45820 and an American Cancer Society Institutional Grant IN-142I.

The publication costs of this article were defrayed in part by payment of page charges. This article must therefore be hereby marked "advertisement" in accordance with 18 USC section 1734 solely to indicate this fact.

\section{References}

Ashburner, M., P. Thompson, J. Roote, P.F. Lasko, Y. Grau, M. El Messal, S. Roth, and P. Simpson. 1990. The genetics of a small autosomal region of Drosophila melanogaster containing the structural gene for alcohol dehydrogenase. VII. Characterization of the region around the snail and cactus loci. Genetics 126: 679-694.

Berleth, T., M. Burri, G. Thoma, D. Bopp, S. Richstein, G. Frigerio, M. Noll, and C. Nüsslein-Volhard. 1988. The role of localization of bicoid RNA in organizing the anterior pattern of the Drosophila embryo. EMBO I. 7: 1749-1756.

Botas, J., J. Moscoso del Prado, and A. Garcia-Bellido. 1982. Gene-dose titration analysis in the search of trans-regulatory genes in Drosophila. EMBO J. 1: 307-310.

Brown, E.H. and R.C. King. 1964. Studies on the events resulting in the formation of an egg chamber in Drosophila melanogaster. Growth 28: 41-81.

Cheung, H.-K., T.L. Serano, and R.S. Cohen. 1992. Evidence for a highly selective RNA transport system and its role in establishing the dorsoventral axis of the Drosophila egg. Development 114: 653-661.

Clifford, R.J. and T. Schüpbach. 1989. Coordinately and differentially mutable activities of torpedo, the Drosophila melanogaster homolog of the vertebrate EGF receptor gene. Genetics 123: 771-787.

Cline, T.W. 1988. Evidence that sisterless- $a$ and sisterless- $b$ are two of the several discrete "numerator elements" of the X/A sex determination signal in Drosophila that switch $S x I$ between two alternative stable expression states. Genetics 119: 829-862.

Cooley, L., R. Kelley, and A. Spradling. 1988. Insertional mutagenesis of the Drosophila genome with single P elements. Science 239: 1121-1128.

Cooley, L., E. Verheyen, and K. Ayers. 1992. chickadee encodes a profilin required for intercellular cytoplasm transport during Drosophila oogenesis. Cell 69: 173-184.

Cox, K.H., D.V. DeLeon, L.M. Angerer, and R.C. Angerer. 1984. Detection of mRNAs in sea urchin embryos by in situ hybridization using asymmetric RNA probes. Dev. Biol. 101: 485-502.

Dalby, B. and D.M. Glover. 1992. 3' Non-translated sequences in Drosophila cyclin B transcripts direct posterior pole ac- 
cumulation late in oogenesis and peri-nuclear association in syncytial embryos. Development 115: 989-997.

Dambly-Chaudière, C., A. Ghysen, L.Y. Jan, and Y.N. Jan. 1988. The determination of sense organs in Drosophila: Interaction of scute with daughterless. Wilhelm Roux's Arch. Dev. Biol. 197: 419-423.

Driever, W. and C. Nüsslein-Volhard. 1988. A gradient of bicoid protein in Drosophila embryos. Cell 54: 83-93.

Ephrussi, A. and R. Lehmann. 1992. Induction of germ cell formation by oskar. Nature 358: 387-392.

Ephrussi, A., L.K. Dickinson, and R. Lehmann 1991. oskar organizes the germ plasm and directs localization of the posterior determinant nanos. Cell 766: 37-50.

Feinberg, A.P. and B. Vogelstein. 1984. Addendum: A technique for radiolabeling DNA restriction endonuclease fragments to high specific activity. Anal. Biochem. 137: 266-267.

Forlani, S., F. Dominique, O. Saget, and E. Mohier. 1993. A regulatory function for $f_{S}(1) K 10$ in the establishment of dorsoventral polarity in the Drosophila egg and embryo. Mech. Dev. 41: 109-120.

Frigerio, D., M. Burri, D. Bopp, S. Baumgartner, and M. Noll. 1986. Structure of the segmentation gene paired and the Drosophila PRD gene set as a part of a gene network. Cell 47: 735-746.

Frohnhöfer, H.G. and C. Nüsslein-Volhard. 1987. Maternal genes required for the anterior localization of bicoid activity in the embryo of Drosophila. Genes \& Dev. 1: 880-890.

Gatignol, A., C. Buckler, and K.-T. Jeang. 1993. Relatedness of an RNA-binding motif in human immunodeficiency virus type 1 TAR RNA-binding protein TRBP to human P1/dsI kinase and Drosophila Staufen. Mol. Cell. Biol. 13: 21932202.

Gavis, E.R. and R. Lehmann. 1992. Localization of nanos RNA controls embryonic polarity. Cell 71: $301-313$.

Goldberg, D.A. 1980. Isolation and partial characterization of the Drosophila alcohol dehydrogenase gene. Proc. Natl. Acad. Sci. 77: 5794-5798.

Goode, S., D. Wright, and A.P. Mahowald. 1992. The neurogenic locus brainiac cooperates with the Drosophila EGF receptor to establish the ovarian follicle and to determine its dorsalventral polarity. Development 116: 177-192.

Haenlin, M., C. Roos, A. Cassab, and E. Mohier. 1987. Oocytespecific transcription of $f_{s}(1) f_{s}(1) K 10$ : A Drosophila gene affecting dorsal-ventral developmental polarity. $E M B O \mathrm{~J}$. 6: $801-807$.

Hiromi, Y., A. Kuroiwa, and W.J. Gehring. 1985. Control elements of the Drosophila segmentation gene fushi tarazu. Cell 43: 603-613.

Hoffmann, F.M. 1991. Drosophila $a b 1$ and genetic redundancy in signal transduction. Trends Genet. 7: 351-355.

Karr, T.L. 1991. Intracellular sperm/egg interactions in Drosophila: A three-dimensional structural analysis of a paternal product in the developing egg. Mech. Dev. 34: 101-112.

Karr, T.L., M.P. Weir, A. Zehra, and T. Kornberg. 1989 Patterns of engrailed protein in early Drosophila embryos. Development 105: 605-612.

Kelley, R.L. 1993. Initial organization of the Drosophila dorsoventral axis depends on an RNA-binding protein encoded by the squid gene. Genes \& Dev. 7: 948-960.

Kenan, D.J., C.C. Query, and J.D. Keene. 1991. RNA recognition: Towards identifying determinants of specificity. Trends Biochem. Sci. 16: 214-220.

Kim, Y.-J. and B.S. Baker. 1993. Isolation of RRM-type RNAbinding protein genes and the analysis of their relatedness by using a numerical approach. Mol. Cell. Biol. 13: 174-183.

Kim-Ha, J., J.L. Smith, and P.M. Macdonald. 1991. oskar mRNA is localized to the posterior pole of the Drosophila oocyte. Cell 66: 23-35.

Kim-Ha, J., P.J. Webster, J.L. Smith, and P.M. Macdonald. 1993. Multiple RNA regulatory elements mediate distinct steps in localization of oskar mRNA. Development 119: 169-178.

King, R.C. 1970. Ovarian development in Drosophila melanogaster. Academic Press, New York.

Lantz, V., L. Ambrosio, and P. Schedl. 1992. The Drosophila orb gene is predicted to encode sex-specific germline RNA-binding proteins and has localized transcripts in ovaries and early embryos. Development 115: 75-88.

Lantz, V., I.S. Chang, J.I. Horabin, D. Bopp, and P. Schedl. 1994. The Drosophila orb RNA-binding protein is required for the formation of the egg chamber and establishment of polarity. Genes \& Dev. (this issue).

Lasko, P.F. 1992. Molecular movements in oocyte patterning and pole cell differentiation. BioEssays 14: 507-512.

Lehmann, R. 1992. Germ-plasm formation and germ-cell determination in Drosophila. Curr. Opin. Genet. Dev. 2: 543549.

Lehmann, R. and C. Nüsslein-Volhard. 1986. Abdominal segmentation, pole cell formation, and embryonic polarity require the localized activity of oskar, a maternal gene in Drosophila. Cell 47: 141-152.

Lindsley, D.L. and G.G. Zimm. 1992. The genome of Drosophila melanogaster. Academic Press, San Diego, CA.

Mahowald, A.P. and M.P. Kambysellis. 1980. Oogenesis. In The genetics and biology of Drosophila (ed. M. Ashburner and T.R.F. Wright), vol. 2, pp. 141-224. Academic Press, New York.

Mahowald, A.P. and J.M. Strasshiem. 1970. Intercellular migration of centrioles in the germarium of Drosophila melanogaster. An electron microscopic study. J. Cell Biol. 45: 306320.

Manseau, L.J. and T. Schüpbach. 1989. cappuccino and spire: Two unique maternal-effect loci required for both the anteroposterior and dorsoventral patterns of the Drosophila embryo. Genes \& Dev. 3: 1437-1452.

McKearin, D.M. and A.C. Spradling. 1990. bag-of-marbles: A Drosophila gene required to initiate both male and female gametogenesis. Genes \& Dev. 4: 2242-2251.

Montell, D.J., H. Keshishian, and A.C. Spradling. 1991. Laser ablation studies of the role of the Drosophila oocyte nucleus in pattern formation. Science 254: 290-293.

Neuman-Silberberg, F.S. and T. Schüpbach. 1993. The Drosophila dorsoventral patterning gene gurken produces a dorsally localized RNA and encodes a TGF $\alpha$-like protein. Cell 75: $165-174$.

Pirrotta, V. 1986. Cloning Drosophila genes. In Drosophila: A practical approach (ed. D.B. Roberts), pp. 83-110. IRL Press, Washington, D.C

Price, J.V., R.J. Clifford, and T. Schüpbach. 1989. The maternal ventralizing locus torpedo is allelic to faint little ball, an embryonic lethal, and encodes the Drosophila EGF receptor homolog. Cell 56: 1085-1092.

Regan, C.L. and M.T. Fuller. 1990. Interacting genes that affect microtubule function in Drosophila melanogaster: Two classes of mutation revert the failure to complement between hay ${ }^{n c 2}$ and mutations in tubulin genes. Genetics 125: 77-90.

Reuter, G., R. Dorn, G. Wustmann, B. Friede, and G. Rauh. 1986. Third chromosome suppressor of position-effect variegation loci in Drosophila melanogaster. Mol. Gen. Genet. 202: 481-487.

Robberson, B.L., G.J. Cote, and S.M. Berget. 1990. Exon definition may facilitate splice site selection in RNAs with mul- 
tiple exons. Mol. Cell. Biol. 10: 84-94.

Robertson, H.M., C.R. Preston, R.W. Phillis, D.M. JohnsonSchlitz, W.K. Benz, and W.R. Engels. 1988. A stable genomic source of $\mathrm{P}$ element transposase in Drosophila melanogaster. Genetics 118: 461-470.

Roth, S., D. Stein, and C. Nüsslein-Volhard. 1989. A gradient of nuclear localization of the dorsal protein determines dorsoventral pattern in the Drosophila embryo. Cell 59: 11891202.

Rubin, G.M. 1991. Signal transduction and the fate of the R7 photoreceptor in Drosophila. Trends Genet. 7: 372-376.

Ruohola-Baker, H., E. Grell, T.-B. Chou, D. Baker, L.Y. Jan, and Y.N. Jan. 1993. Spatially localized Rhomboid is required for establishment of the dorsal-ventral axis in Drosophila oogenesis. Cell 73: 953-965.

Rushlow, C., K. Han, J.L. Manley, and M. Levine. 1989. The graded distribution of the dorsal morphogen is initiated by selective nuclear transport in Drosophila. Cell 59: 11651177.

Sambrook, J., E.F. Fritsch, and T. Maniatis. 1989. Molecular cloning: A laboratory manual, 2nd ed. Cold Spring Harbor Laboratory Press, Cold Spring Harbor, New York.

Schejter, E.D. and B.-Z. Shilo. 1989. The Drosophila EGF receptor homolog (DER) gene is allelic to faint little ball, a locus essential for embryonic development. Cell 56: 1093-1104.

Schüpbach, T. 1987. Germ line and soma cooperate during oogenesis to establish the dorsoventral pattern of egg shell and embryo in Drosophila melanogaster. Cell 49: 699-707.

Schüpbach, T. and E. Wieschaus. 1986. Maternal-effect mutations altering the anterior-posterior pattern of the Drosophila embryo. Wilhelm Roux's Arch. Dev. Biol. 195: 302317.

Schüpbach, T. and E. Wieschaus. 1991. Female sterile mutations on the second chromosome of Drosophila melanogaster. II. Mutations blocking oogenesis or altering egg morphology. Genetics 129: 1119-1136.

Schüpbach, T., R.J. Clifford, L.J. Manseau, and J.V. Price. 1991. Dorsoventral signaling processes in Drosophila oogenesis. In Cell-cell interactions in early development (ed. J. Gerhart), pp. 163-174. Wiley and Sons, Inc., New York.

Spradling, A.C. 1993a. Germline cysts: Communes that work. Cell 72: 649-651.

- Developmental genetics of oogenesis. In The development of Drosophila melanogaster (ed. M. Bate and A. Martinez-Arias), pp. 1-70. Cold Spring Harbor Laboratory Press, Cold Spring Harbor, New York.

Stein, D. and C. Nüsslein-Volhard. 1992. Multiple extracellular activities in Drosophila egg perivitelline fluid are required for establishment of embryonic dorsal-ventral polarity. Cell 68: $429-440$.

Stein, D., S. Roth, E. Vogelsang, and C. Nüsslein-Volhard. 1991. The polarity of the dorsoventral axis in the Drosophila embryo is defined by an extracellular signal. Cell 65: 725-735.

Stephenson, E. and A.P. Mahowald. 1987. Isolation of Drosophila clones encoding maternally-restricted RNAs. Dev. Biol. 24: 1-8.

Steward, R. 1989. Relocalization of the dorsal protein from the cytoplasm to the nucleus correlates with its function. Cell 59: 1179-1188.

Steward, R., S.B. Zusman, L.H. Juang, and P. Schedl. 1988. The dorsal protein is distributed in a gradient in the early Drosophila embryos. Cell 55: 487-495.

St Johnston, D. and C. Nüsslein-Volhard. 1992. The origin of pattern and polarity in the Drosophila embryo. Cell 68: 201219.

St Johnston, D., W. Driever, T. Berleth, S. Richstein, and C.
Nüsslein-Volhard. 1989. Multiple steps in the localization of bicoid RNA to the anterior pole of the Drosophila oocyte. Development (Suppl.) 107: 13-19.

St Johnston, D., D. Beuchle, and C. Nüsslein-Volhard. 1991. staufen, a gene required to localize maternal RNAs in the Drosophila egg. Cell 66: 51-63.

St Johnston, D., N.H. Brown, J.G. Gall, and M. Jantsch. 1992. A conserved double-stranded RNA-binding domain. Proc. Natl. Acad. Sci. 89: 10979-10983.

Suter, B., L.M. Romberg, and R. Steward. 1989. Bicaudal-D, a Drosophila gene involved in developmental asymmetry: Localized transcript accumulation in ovaries and sequence similarity to myosin heavy chain tail domains. Genes \& Dev. 3: $1957-1968$.

Talerico, M. and S.M. Berget. 1990. Effect of $5^{\prime}$ splice site mutations on splicing of the preceding intron. Mol. Cell. Biol. 10: 6299-6305.

Tamkun, J.W., R. Deuring, M.P. Scott, M. Kissinger, A.M. Pattatucci, T.C. Kaufman, and J.A. Kennison. 1992. Brahma: A regulator of Drosophila homeotic genes structurally related to the yeast transcriptional activator SNF2/SWI2. Cell 68: $561-572$.

Tautz, D. and C. Pfeifle. 1989. A non-radioactive in situ hybridization method for the localization of specific RNAs in Drosophila embryos reveals translational control of the segmentation gene hunchback. Chromosoma 98: 81-85.

Theurkauf, W.E., S. Smiley, M.L. Wong, and B.M. Alberts. 1992. Reorganization of the cytoskeleton during Drosophila oogenesis: Implications for axis specification and intercellular transport. Development 115: 923-936.

Torres, M. and L. Sánches. 1989. The scute (T4) gene acts as a numerator element of the X:A signal that determines the state of activity of Sex-lethal in Drosophila. EMBO $J$. 8: 3079-3086.

Wang, C. and R. Lehmann. 1991. nanos acts is the localized posterior determinant in Drosophila. Cell 66: 637-647.

Wieschaus, E. and C. Nüsslein-Volhard. 1986. Looking at embryos. In Drosophila: A practical approach (ed. D.B. Roberts), pp. 199-227. IRL Press, Washington D.C.

Wieschaus, E., J.L. Marsh, and W. Gehring. 1978. fs(1)K10, a germline-dependent female sterile mutation causing abnormal chorion morphology in Drosophila melanogaster. Wilhelm Roux's Arch. Dev. Biol. 184: 75-82.

Xue, F. and L. Cooley. 1993. kelch encodes a component of intercellular bridges in Drosophila egg chambers. Cell 72: 681-693.

Yue, L. and A.C. Spradling. 1992. hu-li tai shao, a gene required for ring canal formation during Drosophila oogenesis, encodes a homolog of adducin. Genes \& Dev. 6: 2443-2454. 


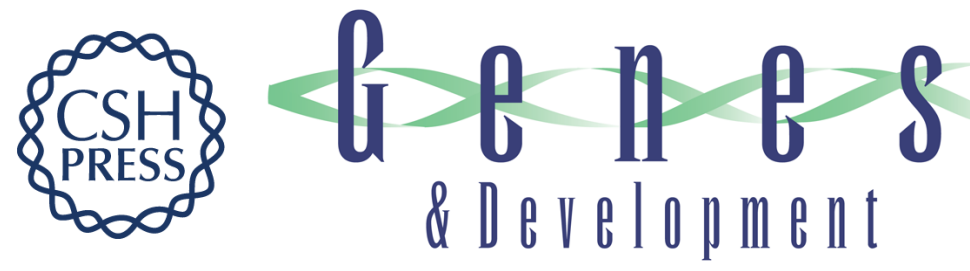

\section{orb is required for anteroposterior and dorsoventral patterning during Drosophila oogenesis.}

L B Christerson and D M McKearin

Genes Dev. 1994, 8:

Access the most recent version at doi:10.1101/gad.8.5.614

References This article cites 75 articles, 29 of which can be accessed free at:

http://genesdev.cshlp.org/content/8/5/614.full.html\#ref-list-1

License

Email Alerting

Service

Receive free email alerts when new articles cite this article - sign up in the box at the top right corner of the article or click here.

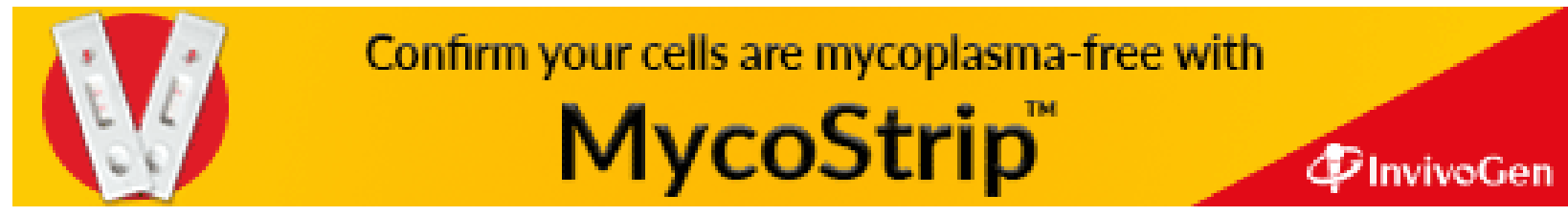

